\title{
Selective Vulnerability of Senescent Glioblastoma Cells to BcI-XL Inhibition
}

\author{
Authors: Masum Rahman*1, Ian Olson*1, Moustafa Mansour ${ }^{1}$, Lucas P. Carlstrom¹, Rujapope \\ Sutiwisesak ${ }^{1}$, Rehan Saber ${ }^{1}$, Karishma Rajani ${ }^{1}$, Arthur E Warrington ${ }^{1}$, Adam Howard ${ }^{1}$, Mark \\ Schroeder ${ }^{1}$, Sisi Chen ${ }^{1}$, Paul A. Decker ${ }^{4}$, Eliot F. Sananikone ${ }^{6}$, Yi Zhu ${ }^{3}$, Ian F. Parney ${ }^{1}$, \\ Sandeep Burma ${ }^{5}$, Desmond Brown ${ }^{1}$, Moses Rodriguez ${ }^{1}$, Jann N. Sarkaria ${ }^{2}$, James Kirkland ${ }^{3}$, \\ Terry C. Burns ${ }^{1}$ \\ ${ }^{\star}$ Equal contribution
}

\author{
Affiliation: \\ ${ }^{1}$ Department of Neurologic Surgery, Mayo Clinic, Rochester MN, USA \\ ${ }^{2}$ Department of Radiation Oncology, Mayo Clinic, Rochester MN, USA. \\ ${ }^{3}$ Robert and Arlene Kogod Center on Aging, Mayo Clinic, Rochester, MN 55905, USA \\ ${ }^{4}$ Department of Biomedical Statistics and Informatics, Mayo Clinic, Rochester MN, USA. \\ ${ }^{5}$ Department of Neurosurgery, Department of Biochemistry and Structural Biology, University of \\ Texas Health Science Center, San Antonio, Texas 78229, USA \\ ${ }^{6}$ Army Public Health Command, Aberdeen Proving Ground, MD 21010, United States
}

\author{
Corresponding Author: \\ Terry C. Burns, M.D., Ph.D., \\ Department of Neurological Surgery, Mayo Clinic \\ 2001 st St SW \\ Rochester, MN 55905 \\ Email: burns.terry@mayo.edu
}

Keywords: Radiation therapy (RT), Glioblastoma (GBM), Recurrent Glioblastoma, Senolytics, Senescence, Tumor microenvironment (TME).

\begin{abstract}
Despite decades of research and numerous basic science advances, there have only marginal gains in improving glioblastoma multiforme survival. Therefore, new ideas and approaches for treating this aggressive disease are essential to drive progress forward. Conventional therapies, such as radiation and Temozolomide (TMZ), function to cause oxidative stress and DNA damage yielding a senescent-like state of replicative arrest in susceptible cells. However, increasing evidence demonstrates malignant cells can escape senescence leading to tumor recurrence. Ablation of non-replicating senescent tumor cells after radiation and chemotherapy may be an avenue to reduce the rates of tumor recurrence. Senolytic agents have been developed that selectively target senescent cells, but it remains unknown whether senolytics might be utilized against senescent-like glioma cells. We employed radiation or TMZ to induce a functionally senescent state in human glioblastoma cells. Viable cells that survive these treatments were then utilized to screen candidate senolytic drugs, to identify those selectively effective at ablating senescent-like cells over naïve non-tumor and proliferative cells. Among 10 candidate senolytic drugs evaluated, only $\mathrm{Bcl}-\mathrm{XL}$ inhibitors demonstrated reproducible senolytic activity in radiated or TMZ-treated glioma across the majority of GBM cell lines evaluated. Conversely, Bcl-2 inhibitors and other established senolytic drugs failed to show any consistent senolytic activity. In agreement with these data, Bcl-XL knockdown selectively reduced the viability of senescent-like GBM cells, whereas knockdown of Bcl-2 or Bcl-W yielded no senolytic effect. These findings demonstrate the potential to harness radiation-induced biology to ablate
\end{abstract}


latent surviving cells and highlight Bcl-XL dependency as a potential vulnerability of surviving GBM cells after exposure to radiation or TMZ.

\section{Introduction}

Gliomas are fatal infiltrative brain tumors for which standard treatment includes maximal surgical resection followed by radiation and Temozolomide (TMZ).[1] Treatment-resistant cells may persist in a latent state for months or years prior to inevitable recurrence. Since surgery is rarely performed until radiographic or symptomatic recurrence, relatively little is known about the molecular characteristics and potential drug sensitivity of the latent human glioma cells that ultimately give rise to recurrence.[2,3,4] Prior work has demonstrated that radiation and TMZ induce a reversible senescent-like phenotype in malignant glioma.[2][5] Senescent cells are characterized by altered transcriptional, metabolic and secretory phenotype all while disconnected from the cell cycle. Although radiation and cytotoxic chemotherapy can induce a senescent-like state of cell cycle arrest in cancer, malignant cells have been shown to escape senescence and re-enter cell cycle, leading to refractory tumor recurrence. [6][7] Recent advances in senescent cell biology have been fueled by evidence that senescent cells underlie mechanisms of aging and aging-associated disease. As such, a growing array of drugs has been identified to ablate senescent cells. Senolytic drugs identified to date target several mechanisms implicated in cancer. Fortunately, many such "senolytic" drugs were originally developed as therapeutics for oncology with toxicity profiles already established in human clinical trials and provide opportunities for more rapid application in other fields where their effects may provide benefit. Since conventional therapy with $T M Z$ and radiation frequently induces a latent period of non-proliferation prior to inevitable recurrence, we investigated whether known senolytic drugs target human GBM cells surviving in a non-proliferative senescent-like state. Herein, we demonstrate that post-chemotherapy or radiation treated GBM cells are selectively vulnerable to BCL-XL inhibition.

\section{Materials and methods:}

\section{Cell culture:}

Human patient-derived glioblastoma lines utilized have been previously described and were cultured according to established protocols.[8] Tumor lines maintained as patient-derived xenografts (PDX) are from the National PDX resource.[8] Such lines are designated as "GBM$6,10,12,39,76,123,164,196$ ". Protocols for implantation of patient-derived Glioblastoma cells, serial passage of flank tumor xenografts, and short-term explant culturing have described previously,[8] with some lines maintained in serum-containing media, and some lines maintained in serum free media as noted in table-2). Some cell lines were maintained from time of harvest as in vitro cell lines rather than PDX lines, as previously reported protocol.[9] Such lines are designated as dBT114,116,120,132(differentiated brain tumor). Culture conditions were unchanged after induction of senescence.

\section{Senescence induction}

After plating, cells were maintained in $10 \mathrm{~cm}$ culture dishes for $2-4$ days until $>50 \%$ confluent. They were then treated with TMZ for 7days or radiation (cesium gamma radiator) with varying doses as indicated.[5][10] Most experiments were performed after use of 15Gy to induce senescence. Radiation and TMZ each caused death of a variable percentage of cells in the ensuing days. "Senescent" tumor cells used for experiments are designated by those that survive following TMZ or radiation treatments. Except for radiation doses of 4Gy or below, no visible proliferation occurred within 1 month after treatment with $\mathrm{TMZ}$ or radiation. For initial screening of senolytic drugs, cells were maintained for at least 20 days after radiation or TMZ 
prior to re-plating cells into black walled optical 96 -well plates (5000cells/well) for doing drug treatment.

\section{Analysis of cell proliferation}

0Gy,4Gy, 8Gy, 15Gy, and 20Gy radiation was delivered as described above. Three days thereafter, cells then plated in 96-well plates. After allowing cells to adhere overnight, they were then placed into the IncuCyte (Thermo Scientific Series 8000 WJ Incubator) and images were captured every four hours for automated quantification of cellular confluence.

\section{Senolytic drug screen}

Human glioblastoma cells were exposed to 10,15 or $20 \mathrm{~Gy}$ radiation as indicated above. All GBM lines tested (Table-2) yielded a subpopulation of surviving non-proliferative cells used for subsequent experiments, with the exception of GM43 which yielded insufficient surviving cells for senescence experiments. All senolytic drugs used in this study were dissolved in DMSO (Table-1). Control (0nM) cells were treated with the same dose of DMSO as cells with the highest drug concentration. Unless specified otherwise, cells were maintained in drugcontaining media for four days prior to evaluation of cell viability using ATP lite, Cell-Titer-Glo assay according to company protocol (Cat\# G7570). For all experiments, luminescence values are normalized to the 0nM control for that cell line and radiation dose. All dose response graphs are depicted standard error of the mean (SEM) of 3 technical replicates at each concentration. Representative data are shown for experiments performed in independent replicates; complete normalized data for all assays performed $(>10,000)$ are provided in online supplemental data.

\section{Evaluation of radiation dose, drug exposure time dependency}

To evaluate the radiation dose effect on BCL-XL inhibitor sensitivity, we radiated GBM39 with 0Gy,1Gy,2Gy,4Gy,8Gy,15Gy. Four days after radiation, cells were plated in black wall 96wells plate. Overnight and drugs added the next day. Seven days after drug treatment, cell viability was measured by Cell Titer-Glo. To determine the impact of varying duration of drug exposure, we plated 15Gy radiated cells 7days after radiation, where the minimum drug exposure time was 1 hour and the maximum 96hours. Cells were plated in black-wall 96-well plates, and drugs added the next day as described above. At the designated time-point, drug-containing media was removed and replaced with drug-free media for the remainder of the experiment (one wash with media, during a replacement). The cell viability assay was performed at the end of 96 hours.

\section{qRT-PCR}

RNA was extracted from cells previously radiated at 15Gy at 1, 3 and 7 days. Briefly, cells were washed with PBS before being homogenized with TriZol reagent (Invitrogen). RNA precipitation was performed at $-20^{\circ} \mathrm{C}$ overnight. Resulting RNA pellets were dissolved in RNase-free water and concentration was measured by absorbance at $260 \mathrm{~nm}$ (A260) using Nanodrop2000. cDNA synthesis was performed with $1 \mathrm{ug}$ of total RNA using M-MLV reverse transcriptase kit (ThermoFisher) as per the manufacturer's protocol. $25 \mathrm{ng}$ of cDNA was used for real-time PCR with Taqman gene expression assay targeting IL-6 (Hs00174131_m1), Bcl-2 (Hs00608023_m1), $\mathrm{Bcl}-\mathrm{XL}$ (Hs001691412_m1) on ABI 7500/7500-Fast Real-Time PCR System (Applied Bioscience). The relative expression of each gene was determined by the $\Delta \Delta C T$ method.

\section{SA- $\beta$-Gal staining}

Senescence-associated $\beta$-galactosidase staining Kit (Cell Signaling Technology \#9860) was used as an indicator of relative senescence after radiation as per the manufacturer's directions. Briefly, cells were fixed for 10 min in $\beta$-galactosidase fixative Solution (10\% 100x Fixative 
Solution; $90 \% \mathrm{H} 2 \mathrm{O}$ ), and washed with PBS. The cells were then stained with $\beta$-Galactosidase Staining Solution (93\% 1x Staining Solution; 1\% 100x Solution A, 1\% 100x Solution B, 5\% Xgal. Wells without samples were filled with PBS, and the plate was wrapped in parafilm to prevent evaporation. The plate was left overnight in a dry incubator at $37^{\circ} \mathrm{C}$. The next day, cells were examined under a microscope for $\beta$-gal-positive cells (blue staining). PBS was added to the wells, and the plate was placed on the rocker (speed $=30 / \mathrm{min}$ ) for 5 minutes. The plate was washed three times. Staining was performed in sham and vehicle-treated control, 10Gy, 15Gy radiated, and TMZ treated GBM39 cells. To see the senescence maturation over time, Beta-Gal staining performed at day 0,7 , and 14 following 15 Gy radiation. For each time points and conditions staining done at multiple wells.

\section{Protein analysis by western blotting}

Cells grown in six-well plates, $10 \mathrm{~cm}$ dishes or T-25 flasks were washed with PBS, trypsinized and collected in 1.5 micro-centrifuge tubes as a cell pellet. The cell pellet was then lysed using lysis buffer composed of 10\% RIPA lysis buffer, 4\% Protease-Inhibitor cocktail, $1 \%$ Phosphatase-Inhibitor cocktail-2, 1\% Phosphatase-Inhibitor cocktail-3, and 84\% Molecular grade water. The cell palate with the lysis buffer then sonicated for 30 minutes in a water bath sonicator (one minute sonication every other minute for a total of 30 minutes). The whole lysate was centrifuged for 10 minutes at the speed of $17,000 \mathrm{~g}$ to collect the supernatant as the final protein lysate. The concentration of the final protein lysate was then measured using the BCA kit (ThermoFischer). Proteins extracted from cells using lysis buffer, were separated in an SDSpolyacrylamide gel electrophoresis along with the protein ladder (Life Technology) using 4-12\% Bis-Tris gel (ThermoFischer). Proteins were then transferred to a polyvinylidene difluoride (PVDF) membrane (Bio-Rad). The membrane was blocked in $5 \%$ fat-free milk (Cell-signaling technology) for 30 minutes, washed three times (5 minutes each) using Tris-buffered saline with tween20 (TBST) and probed with different antibodies (Cell-signaling technology).

\section{Gene knock-down using siRNA}

siRNA sequences were either designed manually using commercially available soft wares or purchased as an already designed sequences (Horizon-ThermoFisher). The siRNA was resuspended in 1X siRNA buffer (Dharmacon) or in any other Nuclease-free solutions. Cells were plated overnight with the optimal density in six-well plates $\left(4 \times 10^{5}\right.$ per well) or 96 -well plates $\left(2 \times 10^{4}\right.$ per well) in antibiotic-free medium. The next day, the transfection complex was prepared by mixing the siRNA (either for the gene of interest or the negative siRNA control) and Lipofectamine RNAiMAX (Invitrogen) in serum-free medium, 250uL from the transfection complex were added to each well of the six-well plate and $10 \mu \mathrm{L}$ for each well in 96-well plate. One day post transfection RNA was collected to be analyzed by qRT-PCR to confirm gene silencing. 2-3 days post transfection, protein was collected to be analyzed by the SDS-page and western blotting to confirm gene silencing. Three days post transfection, the cell viability in response gene silencing was measured using Cell Titer-Glo assay (Promega), and the cell survival ratio was calculated compared to the negatively silenced control cells.

\section{Statistical analysis}

Multiple linear regressions were used to assess the relationship of drug dose and treatment (e.g. control, radiation, TMZ) with cell inhibition within each cell line. For these models, cell inhibition was the outcome and drug dose, treatment, and the drug dose by treatment interaction were the independent predictors. If the drug dose by treatment interaction was significant $(p<0.05)$, pairwise comparisons were made at each drug dose between treatment groups using a two- 
sample t-test. Statistical analysis was performed in Microsoft Excel. IC50 was calculated by nonlinear regression (Curve fit) of dose-response inhibition curve by using GraphPad prism 8.4.2.

\section{Results}

Chemoradiation induces a senescence-like state of sustained proliferative arrest. We sought to test the hypothesis that glioblastoma could be relatively more sensitive to senolytic ablative therapies when induced into a senescent-like state of proliferative arrest following radiation.[10][11] No phenotypic marker is perfectly sensitive or specific for senescence. Indeed, significant overlap exists between phenotypic characteristics of malignant and senescent cells.[12][13] However, while malignant cells are defined in part by proliferative behavior, senescent cells, by definition, do not divide. We evaluated single fraction radiation doses in human glioblastoma cell lines and observed sustained loss of culture expansion with $8 \mathrm{~Gy}$ or higher radiation in the GBM39 cell line (Figure 1). Senescent-like cultures demonstrated evidence of increased SA- $\beta$ gal staining; consistent with a senescent phenotype induced by radiation (Figure 1A, Supp Fig-7A-C).[10] Higher expression of the senescence-associated gene, p21, and the anti-apoptotic pathway up-regulation, was also apparent in residual cells over seven days following radiation (Supp Fig-7D).

\section{Radiated GBM cell lines selectively vulnerable anti-Bcl-2 family agents}

A growing variety of drugs have been proposed as having senolytic activity. Consistent with certain overlapping biology between senescence and malignancy, some senolytic drugs have known anti-tumor activity.[12][14] We investigated whether prior radiation increases sensitivity to senolytic agents. The senolytic drugs tested and their associated senescent cell associated pathways (SCAPs) are detailed in Table 1. [14] Irradiated cell lines GBM39 and GBM76 both demonstrated relatively higher sensitivity to the Bcl-2 family targeting drugs A1331852 (mean $+/-S D$, range for each cell line) and Navitoclax (mean +/-SD, range for each cell line) than nonradiated cells $(\mathrm{p}<0.0001)$ (Figure 2 , Supp Figure-1). Both target the Bcl-2 family of anti-apoptotic proteins. Specifically, Navitoclax targets Bcl-2 and Bcl-XL, whereas A1331852 targets Bcl-XL only.[15][16]

To further discriminate between the dependence of radiated human GBM upon Bcl-XL and Bcl2, we evaluated Navitoclax and A1331852, as well as A1155463- a Bcl-XL-selective inhibitor, and Venetoclax, a Bcl-2-selective inhibitor.[17] For reference, the previously published Ki values for each of these 4 drugs for anti-apoptotic Bcl-2 family members (Bcl-XL, BCl-2 and Bcl-W) is shown in table 4. To date, no drug is available to selectively inhibit Bcl-W. Ablation of radiated cells was seen across all lines (GBM10, 39, 76, 123), for all drugs, except for Venetoclax (Figure 3). Three of four lines showed no selective ablation with Venetoclax; lower viability was seen with high dose Venetoclax in radiated GBM 10 cells. These data suggested $\mathrm{Bcl}-\mathrm{XL}$ to be the most relevant therapeutic target for ablation of previously radiated senescentlike GBM. To further evaluate the reproducibility of Bcl-XL dependence in radiated human glioblastoma, we tested A1331852 and/or Navitoclax in several additional molecularly diverse cell lines with and without prior 10, 15 or 20Gy radiation (Supp Figure-3). The molecular characteristics of the cell lines utilized are summarized in table 2. Among the 13 human GBM cell lines evaluated, meaningful analysis was possible in all with the exception of GBM43, for which insufficient cells survived radiation to permit testing. Results of the pharmacologic Bcl-XL inhibition studies performed are summarized in table 3 and Figure-7. While the IC50 of Bcl-XL inhibition with and without radiation varied markedly between lines, radiated GBM was reproducibly more susceptible to Bcl-XL inhibition than non-radiated GBM. 


\section{Time-point of BCL-XL inhibitor sensitivity}

The previous experiments maintained radiated cells for 2-4 weeks after radiation prior to senolytic drug testing. While the senescence process often takes weeks, the apoptotic pathways regulated by bcl-2 family members are dynamically regulated within days following DNA damage. As such, we used GBM39 to ask if a minimal period of time after radiation must elapse following radiation prior to onset of Bcl-XL sensitivity. Using a timed assay following radiation, GBM39 was treated with Bcl-XL inhibitors A1331852 or A1155463 for 4 days, starting 1,5 , or 9 days after radiation. Analysis was performed at the end of the 4 days drug exposure. While efficacy was seen upon treatment starting one day after radiation, more complete cell ablation was observed with a leftward shift of the dose response curve, four days elapsed after radiation prior to starting treatment 5 or 9 days following radiation (Fig 4A and Sup Fig 4B).

\section{Dependency on drug exposure time and radiation dose}

We next asked if a minimal radiation dose was required to induce susceptibility cell death with Bcl-XL inhibition. Radiation doses of 4Gy or higher in GBM39 promoted sensitivity to A1331852 with increasing efficacy up to 15Gy (Fig 4B). For most cell lines, radiation doses of 10-20Gy yielded similar results (Sup fig 3, and Table 3). In anticipation of future considerations related therapeutic dosing, we next asked what duration of continuous BCL-XL inhibitor exposure may be required to observe senolytic effect. To accomplish this, GBM39 was exposed to drug for varying durations from 0-96 hours, with drug then washed off and cells maintained in normal growth media thereafter until time of analysis. Although some most impact was observed even with 1 hour of treatment, maximal impact was seen in cells that received sustained exposure to Bcl-XL inhibition for 96hours.

\section{Elimination of TMZ treated senescent glioma}

Radiation and TMZ are both routinely administered to patients with GBM. Both may induce senescence and modulate apoptotic machinery. To determine whether TMZ (100uM) exposure induces selective susceptibility to BCL-XL inhibition, we pre-treated the GBM cell lines with TMZ for 20 days and then analyzed various anti-Bcl-family agents. Using GBM76, and GBM39, we found that prior 20 days TMZ exposure induced sensitivity to the BCL-XL inhibition, but not BCL-2 inhibition as previously observed following radiation (Figure 4 and Supp Figure 4).

Based on the previously published selectivity of A1331852, A1155463 to Bcl-XL and Venetoclax to $\mathrm{Bcl}-2$ (table 4), we predicted that knockdown of Bcl-XL but not Bcl2 would impede survival in radiated cells. We utilized siRNA constructs and scrambled controls and evaluated their impact on survival in radiated and non-radiate GBM. Compared to scrambled controls, Bcl-2 and Bcl-W knockdown elicited no impact on cell survival whereas Bcl-XL knockdown significantly decreased survival of radiated cells.

Finally, we investigated whether prior cytotoxic therapy would be sufficient to permanently induce sensitivity to $\mathrm{Bcl}-\mathrm{XL}$ blockade, or if cells must remain in a senescent-like non-proliferative state to maintain sensitivity. In one culture maintained over 6 weeks following 8 Gy radiation, proliferative activity resumed, with a doubling time ultimately unchanged from the parent culture. Cells in the culture that "escaped senescence" to resume proliferative behavior lost sensitivity to Bcl-XL inhibition (Supp Figure 5). This result is consistent with the observation that gliomas derived from both primary and recurrent lesions (Supp Figure 3) proved relatively insensitive to $\mathrm{Bcl}-\mathrm{XL}$ inhibition until placed into a state of proliferative arrest with either TMZ or radiation. 


\section{Discussion}

We here demonstrate that human GBM cells surviving in a senescent-like state after chemotherapy or TMZ are relatively more susceptible to BCL-XL-blockade than naïve proliferative GBM. Conventional cancer therapies such as radiation and alkylating chemotherapies act through induction of oxidative stress and DNA damage. [18][19] These can exert therapeutic impact through multiple mechanisms: (i) lethal cell damage (ii) inducing a senescent-like state of proliferative arrest that impedes further growth,[20] (iii) promoting a state of tumor quiescence to attenuate proliferation, and/or (iv)altering the tumor microenvironment or tumor-immune response to indirectly achieve some combination of the first three goals.[21]

That gliomas invariably recur highlights the inadequate levels of lethal cell damage achieved with standard chemoradiation. Gliomas are well described to harbor a population of relatively quiescent and resilient glioma stem cells.[7][22][23] Some have interpreted glioma recurrence as evidence that quiescent "glioma stem cells" persist in a quiescent state after chemoradiation prior to ultimately re-initiating tumor recurrence.[24] Other evidence in glioma and other tumors supports induction of a senescent-like state, after cytotoxic therapy. If indeed quiescent glioma stem cells and senescent cells both exist in glioma after standard therapy, do they both actively coexist in parallel at all points following therapy, or could initially senescent cells escape senescence to revitalize the tumor as quiescent stem cells? Recent work showed that that cancer cells with an initially senescent phenotype following chemotherapy escaped senescence upon p53 inhibition giving rise to tumor stem cells that were more aggressive and resilient than those present in the original tumor.[25][26] If true for glioma, senolytic therapies could help eliminate senescent glioma cells before they have the chance to re-emerge as quiescent glioma stem cells. Indeed, we found that in one culture of GBM39 that eventually re-entered cell cycle 6 weeks after $8 \mathrm{~Gy}$, proved highly resistant even to unable to promote apoptosis, even at doses that had been effective prior to the original radiation.

Conversely, four of the GBM lines used $(10,76,120,123)$ were derived from patient with recurrent tumors who had previously undergone chemotherapy and radiation.[27] Although GBM123 was among the weaker responders, all others showed similarly augmented response to BCL-XL inhibition after re-induction of senescence with radiation or TMZ. Also of note, certain lines tested (including GBM 6 and 10) have been previously reported as radio-resistant with nominal prolongation of survival in xenografts upon radiation. Nevertheless, these were amenable to sufficient proliferative arrest in vitro, to permit augmented ablation with BCL-XL inhibition.

p53 is a key regulator of cell cycle arrest in the context of radiation-induced DNA damage and senescence, and is the most commonly mutated gene across human cancers.[28][29] Although several lines with some of the most robust relative sensitivity to BCL-XL (in radiated vs nonradiated cells) were WT for p53 (e.g., GBM 10, 39, 76, 114), highly significant induction was also observed in p53-mutant cell lines (GBM 6, 12, 132, 196). Similarly, no clear p53 pattern followed for cells with modest radiation-induced induction BCL-XL inhibitor sensitivity: P53-mutant GBM123 showed only 2.5x induction of A1331852 sensitivity (results were more robust for A1155 and Navitoclax, Figure 3), yet p53-WT GBM 164 showed minimally significant difference between radiated and non-radiated cells for both A133A852 and Navitoclax. That 11 of 12 tested lines showed significant induction of sensitivity to one or more BCL-XL inhibitors with radiation supports the broadly reproducible phenomenon across molecularly diverse GBM 
It is likely that additional stimuli besides radiation and alkylating chemotherapy may augment sensitivity to $\mathrm{BCl}-\mathrm{XL}$ inhibition. Massler, et al., previously reported induction of synthetic lethality with BCL-XL inhibition in IDH-mutant gliomas, or upon induction of the on cometabolite D2-HG produced by IDH-mutant gliomas. [30] Their study specifically utilized GBM164, which they observed to have a robust sensitivity to BCL-XL. Indeed, among the 12 lines tested, GBM164 was one of the two most sensitive prior to radiation. However, the most sensitive line was GBM 12, which is IDH wild-type. We additionally evaluated another line which unlike GBM196, which is homozygous for IDH1-R132H, in contrast to GBM164 which is heterozygous for IDH1-R132H. Accordingly, GBM196 generates higher levels of D2-HG (not shown), yet demonstrated $\sim 100 x$ lower baseline sensitivity to A1331852 than GBM164. While we did not independently evaluate the impact of D2-HG on BCL-XL inhibition in this study, data obtained in this study would have not provided a rationale to do so. Rather, our data indicate that baseline sensitivity to BCL-XL inhibition may vary widely among both IDH-mutant and IDH-WT cell lines. However, in $90 \%$ of cases, radiation exposure was observed to enhance radiation sensitivity. It should also be noted that baseline sensitivity to BCL-XL was not predictive of the degree of final BCL-XL sensitivity achievable after exposure to radiation or TMZ. Indeed, certain lines with negligible baseline sensitivity (e.g. GBM39) were induced by radiation to be among the most sensitive after radiation.

As such, while some molecular therapies can be selectively targeted to specific tumor subtypes, we don't our current data with only 12 cell lines divergent across phenotypes for EGFR, PTEN, CDKN2A, P53, as well as gender, age, MGMT methylation, molecular subtype and recurrence status revealed no specific molecular phenotype that would obviously portend poor response to $\mathrm{Bcl}-\mathrm{XL}$ inhibition. Rather, we speculate that the therapy-induced sensitivity to Bcl-XL dependency may be mechanistically linked to intracellular processes subserving and maintaining a molecular mediator of proliferative arrest, and could thus be synergistic with therapies that activate appropriate mitotic checkpoint machinery. [31] Among master regulators of cellular senescence, a mechanistic role of $\mathrm{p} 16$ is largely excluded by virtue of most tested lines being homozygous null for CDKN2A, which encodes p16, an inhibitor of CDK4/6.[32][33][34] This could by implication reduce the probability of synergy between $\mathrm{Bcl}-\mathrm{XL}$ inhibitors with $\mathrm{CDK} 4 / 6$ inhibitors, though also induce senescence, at least in regards to $\mathrm{Bcl}-\mathrm{XL}$ inhibition. Conversely, p21 is almost ubiquitously conserved in glioma, is frequently overexpressed in glioma and is upregulated by radiationinduced DNA damage, providing an attractive avenue for future mechanistic investigations. While P21 is upregulated by p53 which is mutant in many GBMs, p21 is also regulated by other pathways and the interactions between mutant p53 and p21 can be paradoxical in cancer.

Recent work demonstrated that systemic Navitoclax was effective to prolong survival of GBM164 in a xenograft model.[30] If BBB penetration were equivalent across cell lines, this would suggest that GBM 114, 116, 120 and 76, 39, and 12 should exhibit comparable or better sensitivity after chemotherapy and/or radiation, whereas even radiated GBM 132, 10 and 123 and 196 each maintained an in vitro IC50 >10x that of non-radiated GBM164 and may thus be more resistant. Efficacy of Navitoclax as a senolytic was recently demonstrated in a tauopathy model of Alzheimer's disease suggesting that BBB disruption may not be required for efficacy.[35] Moreover, to the extent that radiation-induced senescence may contribute to radiation-induced cognitive impairment, concurrent ablation of senescent host cells could provide a cognitively beneficial adjunct to senescent tumor ablation.[36]

While senescence serves to attenuate cell-intrinsic proliferation, SASP factors produced by senescent cells have been shown to promote tumor infiltration and recruitment of pro-tumorigenic tumor-associated macrophages. We and others have observed increased aggressiveness of human glioma implanted into the previously radiated brain. Whether this phenomenon could be attenuated with senolytics is under investigation. However, the phenomenon of "senescent 
spreading" has been proposed as a means via which senescent cells could actually attenuate proliferation of adjacent tumor cells. The diversity of responses to BCL-XL inhibition in absence of clear phenotypic correlates suggest empiric studies will be required to discriminate among these possibilities.

The present study provides our first attempt to harness the senescent-like biology of treated human GBM to facilitate the clearance of dormant cells. An obvious limitation of this work is that in vitro cultures offer notoriously poor surrogates of the in vivo human glioma microenvironment. A dedicated effort to rigorously characterize the senescent tumor is of high importance. Efforts to do so for human glioma may be hampered by the rarity of surgery for dormant disease, as well as the likely paucity of the offending latent cells, as well as inherent inability to expand senescent cells. As such best available models will be needed to determine if the senescent-like state of sustained proliferative arrest seen vitro, might be antagonized by complex in vivo biology. For example, tumor-associated hypoxia in vivo with its relative nutrient deprivation may attenuate mTOR signaling which is important to achieve a stably senescent cell phenotype-Bcl-XL-related implications of which are unclear. Moreover, the complex tumor microenvironment will predictably endow malignant cells with diverse sources of trophic support that are lacking in vitro potentially requiring adjuvant strategies not anticipated from in vitro analyses.[37]

In conclusion, we demonstrate that radiation and TMZ endow glioma with increased dependence upon $\mathrm{Bcl}-\mathrm{XL}$, blockade of which may facilitate ablation of latent glioma cells that survived prior cytotoxic therapy. Since radiation and TMZ are standard of care for GBM, further work is needed to determine if $\mathrm{Bcl}-\mathrm{XL}$ inhibition could be leveraged to help forestall glioma recurrence.

Table 1 [38]

\begin{tabular}{|l|l|}
\hline Senescent Cell Anti-Apoptotic Pathways (SCAPS) & Inhibitors \\
\hline 1. PI3Kō, AKT, ROS-protective, metabolic & Quercetin, Fisetin, Piperlongumine \\
\hline 2. MDM2, p53, p21, serpine & Quercetin, Fisetin, Dasatinib \\
\hline 3. Bcl-2 & Navitoclax, Venitoclax \\
\hline 4. Bcl-XL & Navitoclax, A1331852, A1155463 \\
\hline 5. Ephrins, dependence receptors, tyrosine kinases & Dasatinib, Piperlongumine \\
\hline 6. HIF-1 ${ }^{a}$ & Quercetin, Fisetin \\
\hline 7. HSP-90 & Onalespib \\
\hline
\end{tabular}


bioRxiv preprint doi: https://doi.org/10.1101/2020.06.03.132712; this version posted June 22, 2020. The copyright holder for this preprint (which was not certified by peer review) is the author/funder, who has granted bioRxiv a license to display the preprint in perpetuity. It is made available under aCC-BY 4.0 International license.

Table.2 [27]

\begin{tabular}{|c|c|c|c|c|c|c|c|c|c|c|c|c|}
\hline Line & $\begin{array}{l}\mathrm{Se} \\
\mathrm{x} \\
\mathrm{M}\end{array}$ & 65 & $\begin{array}{l}\text { Recurrence } \\
\text { Status } \\
\text { Primary }\end{array}$ & $\begin{array}{l}\text { MGMT } \\
\text { methyl- } \\
\text { ation } \\
\text { U }\end{array}$ & $\begin{array}{l}\text { Sub- } \\
\text { type } \\
\text { Clas }\end{array}$ & IDH1 & $\begin{array}{l}\text { CDKN2 } \\
\text { A } \\
\text { LL }\end{array}$ & PTEN & $\mathrm{A}(\mathrm{v} 3)$ & TP53 & Met & $\begin{array}{l}\text { Tert } \\
\text { Prom } \\
\text { M }\end{array}$ \\
\hline 10 & $M$ & 41 & Recurrent & $\mathrm{U}$ & Mes & & $\mathrm{LL}$ & LM & $A$ & & $A$ & $M$ \\
\hline 12 & $M$ & 68 & Primary & $M$ & Mes & & LL & & $\mathrm{AM}$ & $\overline{M L}$ & & $M$ \\
\hline 39 & $M$ & 51 & Primary & $M$ & Mes & & $\mathrm{L}$ & LM & $\mathrm{A}(\mathrm{v} 3)$ & & A & $M$ \\
\hline 43 & $M$ & 69 & Primary & $\mathrm{U}$ & Mes & & $\mathrm{LL}$ & & & $M$ & & $M$ \\
\hline 76 & $M$ & 38 & Recurrent & $M$ & Clas & & $\mathrm{LL}$ & LM & $\mathrm{A}(\mathrm{v} 3)$ & & A & $M$ \\
\hline $114^{*}$ & $M$ & 68 & Primary & $M$ & ND & & LL & $\mathrm{L}$ & A & & & $M$ \\
\hline $116^{*}$ & $F$ & 56 & Primary & $M$ & Mes & & $\mathrm{LL}$ & LM & A & $M$ & A & $M$ \\
\hline $120^{*}$ & $M$ & 57 & Recurrent & $\mathrm{U}$ & PN & & $A$ & $\mathrm{LL}$ & $A$ & $M$ & A & $M$ \\
\hline 123 & $F$ & 62 & Recurrent & $\mathrm{U}$ & PN & & & $\mathrm{L}$ & $\mathrm{A}(\mathrm{v} 2)$ & $M$ & & $M$ \\
\hline $132^{*}$ & $M$ & 75 & Primary & $\mathrm{U}$ & Clas & & $\mathrm{L}$ & $\mathrm{L}$ & $A$ & $M$ & & $M$ \\
\hline 164 & $F$ & 38 & Primary & $M$ & $\mathrm{PN}$ & $M^{h}$ & $\mathrm{LL}$ & $\mathrm{L}$ & & & $A$ & - \\
\hline 196 & $F$ & 30 & Primary & $M$ & ND & $\mathrm{M}^{\mathrm{hh}}$ & LL & $\mathrm{L}$ & $A$ & MA & A & - \\
\hline
\end{tabular}

${ }^{*}=\mathrm{dBT}$ ("differentiated brain tumor - aka, maintained in culture).

M=Mutant

$A=$ Amplified or net gain $(>2 n)$

L=Loss

$\mathrm{LL}=$ Homozygous deletion

Subtypes: Classical (Clas), Mesenchymal (Mes), Proneural (P), Not determined (ND)

${ }^{\mathrm{h}}$ heterozygous IDH R132H mutation

hh homozygous IDH R132H mutation

v2, v3 = EGFR variants. 
Table-3: IC50 of A1331852(uM)

\begin{tabular}{|c|c|c|c|c|c|c|}
\hline $\begin{array}{l}\text { Cell lines } \\
\text { (passage } \\
\text { number) } \\
6(\mathrm{P} 4)\end{array}$ & Control & 2.26 & $\begin{array}{l}\text { Relative } \\
\text { sensitivity } \\
\text { (RS) } \\
6.251327434\end{array}$ & $\begin{array}{l}\text { Treatment } \\
\text { 10Gy }\end{array}$ & $\begin{array}{l}\text { P value } \\
p<0.0001\end{array}$ & $\begin{array}{l}\mathrm{N} \text { of } \\
\text { experi } \\
\text { ments } \\
1\end{array}$ \\
\hline $6(\mathrm{P} 4)$ & 14.128 & 0.5316 & 26.57637 & $15 \mathrm{~Gy}$ & $p<0.0001$ & 1 \\
\hline $6(\mathrm{P} 4)$ & 14.128 & 0.8452 & 16.71557 & 20Gy & $p<0.0001$ & 1 \\
\hline $10(\mathrm{P} 2)$ & 39.97 & 2.469 & 16.18874 & 15Gy & $\mathrm{p}<0.0001$ & 1 \\
\hline $12(\mathrm{P} 3)$ & $0.39 \pm 0.07$ & $0.0229 \pm 0.00761$ & $\begin{array}{l}19.7362 \\
\pm 8.282214\end{array}$ & $15 \mathrm{~Gy}$ & $p<0.0001$ & 3 \\
\hline $39(\mathrm{P} 2-3)$ & $107.8895 \pm 152.35$ & $0.080547 \pm 0.093$ & $\begin{array}{l}513.8149 \\
\pm 711.64\end{array}$ & 15Gy & $p<0.0001$ & 3 \\
\hline $39(\mathrm{P} 3)$ & $1.30465 \pm 1.01435$ & $0.071 \pm 0.010255$ & $\begin{array}{l}16.65831 \\
\pm 11.87971\end{array}$ & 20Gy & $p<0.0001$ & 2 \\
\hline $39(\mathrm{P} 2-3)$ & $1.7164 \pm 2.1821$ & $\begin{array}{l}0.041846 \pm 2.182 \\
1\end{array}$ & $\begin{array}{l}41.01706 \\
\pm 2.182154\end{array}$ & TMZ(100uM) & $p<0.0001$ & 3 \\
\hline $76(\mathrm{P} 2)$ & $23.464 \pm 6.762$ & $0.9998 \pm 0.36727$ & $\begin{array}{l}31.77018 \\
\pm 23.61\end{array}$ & 10Gy & $p<0.0001$ & 3 \\
\hline $76(\mathrm{P} 2)$ & $23.464 \pm 6.7622$ & $1.225 \pm 0.41632$ & $\begin{array}{l}20.64494 \\
\pm 5.632602\end{array}$ & 15Gy & $p<0.0001$ & 3 \\
\hline 76(P2)- & $\begin{array}{l}23.464 \\
\pm 6.762161\end{array}$ & $0.679 \pm 0.049209$ & $\begin{array}{l}34.24256 \\
\pm 7.988135\end{array}$ & $20 \mathrm{~Gy}$ & $p<0.0001$ & 3 \\
\hline 76(P3)- & 1.685 & 0.05973 & 28.21028 & TMZ(100uM) & $p<0.0001$ & 1 \\
\hline 114(P11)* & $6.3175 \pm 1.0925$ & $\begin{array}{l}0.33825 \\
\pm 0.07205\end{array}$ & $20.28 \pm 7.55$ & $15 \mathrm{~Gy}$ & $p<0.0001$ & 2 \\
\hline $116(\mathrm{P} 8)^{*}$ & 0.2899 & 0.06349 & 4.566073 & 20Gy & $p<0.0001$ & 1 \\
\hline $120(\mathrm{P} 10)^{*}$ & 5.179 & 0.4581 & 11.30539 & 15Gy & $p<0.0001$ & 1 \\
\hline 123(P3) & 22.991 & 9.356 & 2.457354 & 15Gy & $P=0.0532$ & 1 \\
\hline 132(P10)* & 18.166 & 4.311 & 4.213871 & 10Gy & $p<0.0001$ & 1 \\
\hline 132(P10)* & 18.166 & 2.934 & 6.191547 & 20Gy & $p<0.0001$ & 1 \\
\hline 164(P2) & 0.2973 & 0.07774 & 3.824286 & 15Gy & & 1 \\
\hline 196(P2) & 27.336 & 2.549 & 10.72420557 & $15 \mathrm{~Gy}$ & $p<0.0001$ & 1 \\
\hline
\end{tabular}

Relative sensitivity = fold changes of IC50 comparing to IC50 of control cells

$*=\mathrm{dBT}$ (maintained in culture) 
Table 4 [39][40]

\begin{tabular}{|l|l|l|l|l|}
\hline Inhibitors & $\begin{array}{l}\text { BCL-XL } \\
\text { Ki(nM) }\end{array}$ & $\begin{array}{l}\text { BCL-2 } \\
\text { Ki(nM) }\end{array}$ & $\begin{array}{l}\text { BCL-W } \\
\text { Ki(nM) }\end{array}$ & Comment \\
\hline Navitoclax & 0.055 & 0.044 & 21 & 4 \\
A1331852 & $<0.010$ & 6 & $\begin{array}{l}\text { BCL-XL,BCL-2 } \\
\text { dual inhibitor } \\
\text { BCL-XL specific } \\
\text { inhibitor }\end{array}$ \\
\hline A1155463 & $<0.010$ & 74 & $\begin{array}{l}\text { BCL-XL specific } \\
\text { inhibitor }\end{array}$ \\
\hline Venetoclax & 48 & $<0.010$ & 245 & $\begin{array}{l}\text { BCL-2 specific } \\
\text { inhibitor }\end{array}$ \\
\hline
\end{tabular}

The inhibition constant, $\mathrm{Ki}$, denotes the equilibrium constant- the concentration of drug needed to occupy half the free protein. Lower Ki indicates higher affinity. 
A

\section{GBM 39}
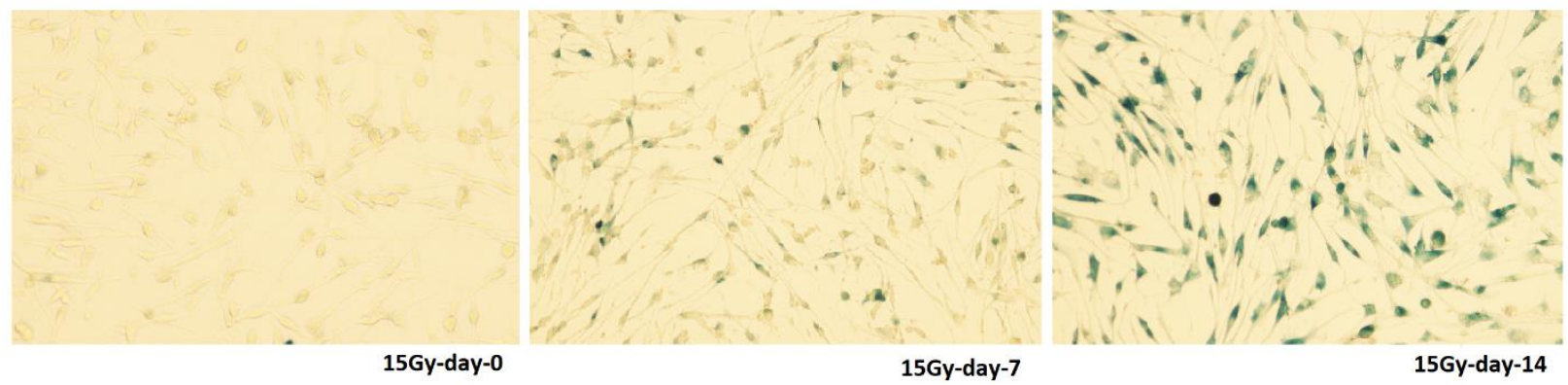

B

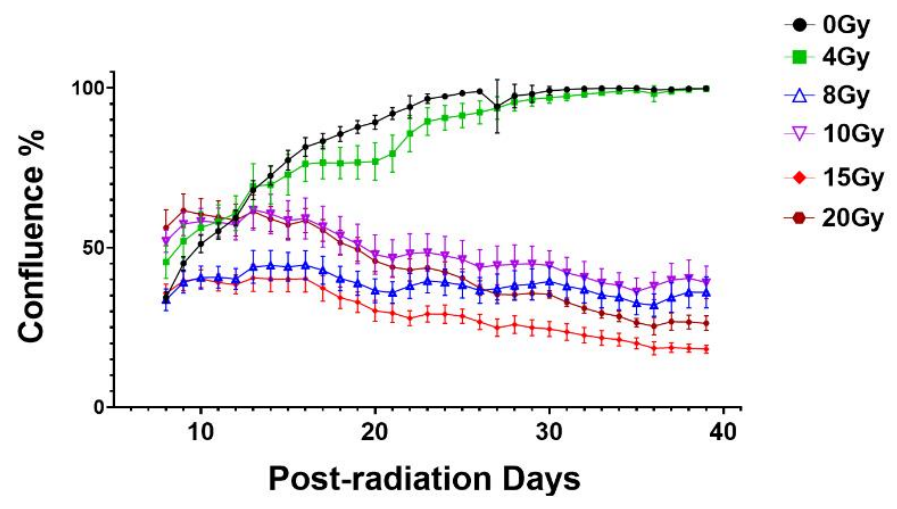

Figure 1: Radiation of GBM cells in vitro induces a senescent-like phenotype. A: Increased SA-Beta-Galactosidase staining in GBM 39 over 14 days following 15 Gy radiation. B: Change in GB39 confluency in vitro over 40 days following radiation doses from 0-20Gy. Error bars show SEM from technical replicates. 
GBM 39



$p=0.0078$

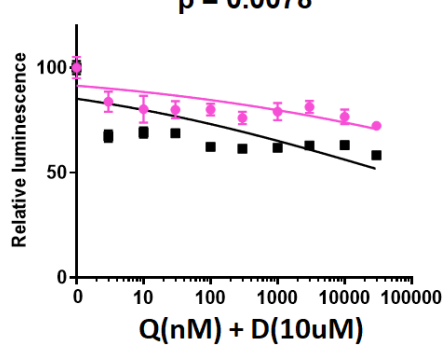

$p=0.0010$

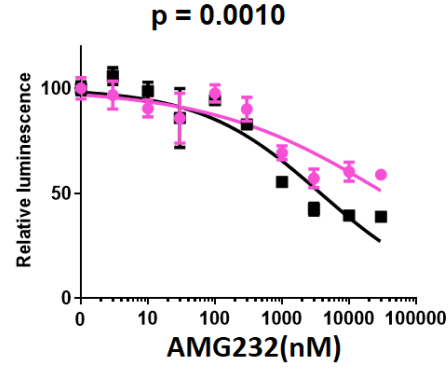

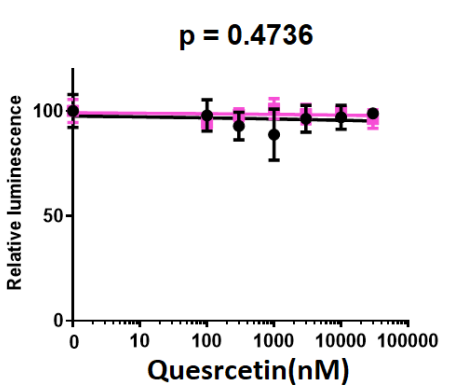

$p=0.0268$


Non-radiated $\neg$ 15Gy radiated


Figure 2: Navitoclax and A1331852 ablate radiated GBM39. Candidate senolytic drugs were evaluated using GBM39: Drug screening was performed 21 days after radiation. Cells were exposed to drugs for four days prior analysis via Cell-Titer-Glo. Purple line and black lines denote the dose-response curve for 15Gy and 0Gy radiated cells, respectively. Luminescence values are normalized to 0nM control for each radiation dose. Navitoclax and A1331852 demonstrated lower IC50 in radiated cells, $p<0.0001$. The data shown are means $\pm S E M$ (standard error of mean) of 3 technical replicates; similar results were obtained in GBM39 with 10 or 20 Gy and GBM76 after 10, 15 or 20Gy (see Supp. fig-1) 


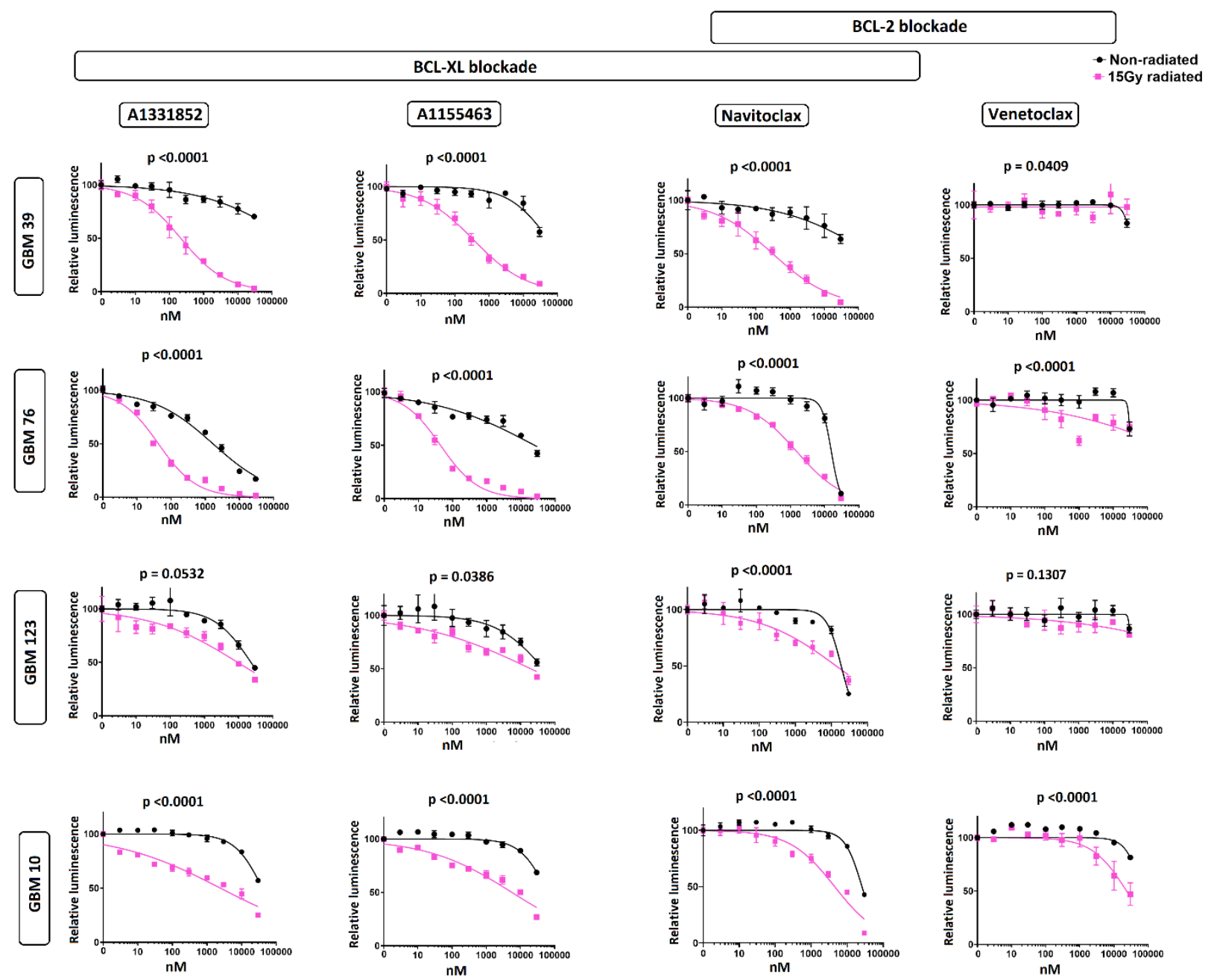

Figure 3: Radiated GBM cell lines are selectively vulnerable to Bcl-XL blockade. GBM39, 76, 10 and 123 were used to evaluate the senolytic activity of BCL2-family inhibitors, including the BCL-XL-specific inhibitors (A1331852, A1155463), the selective BCL-2inhibitor (Venetoclax) and dual inhibitor of both BCL-XL and BCL-2 (Navitoclax). Dose response curves shown for control non-radiated (black) and 15Gy radiated (purple) cells. Cells were exposed to drug for 4 days, starting 21 days after radiation. 15Gy-radiated cells demonstrated higher sensitivity than non-radiated cells to the BCL-X-selective inhibitors (A1331852, A1155463), and Navitoclax (Inhibits Bcl-XL and Bcl-2) but, not Venetoclax (BCL-2-selective inhibitor). For all groups, luminescence values are normalized individually to $0 \mathrm{nM}$ control. Data shown are means ${ }_{ \pm} \mathrm{SEM}$ of 3 technical replicates at each concentration. Data shown are representative of multiple confirmatory experiments. Complete data for each cell line and condition are available in supplemental table-3. 

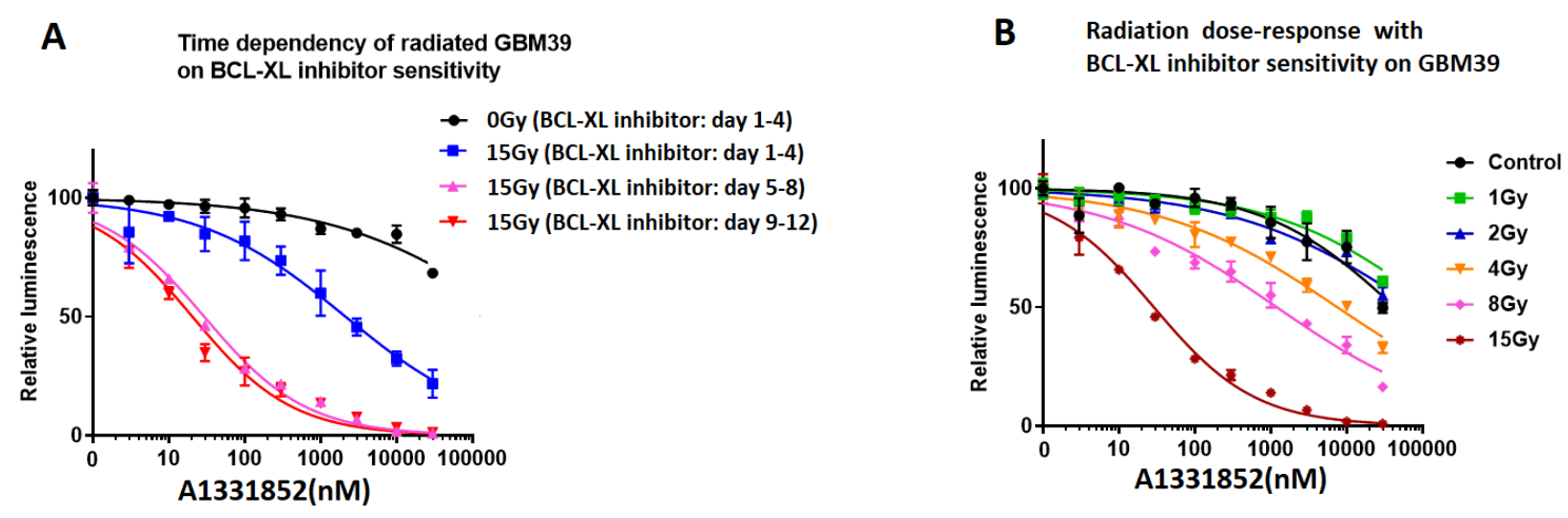

C

Drug exposure time effect on 15Gy radiated GBM39



Figure 4: GBM vulnerability to $B C L-X L$ inhibition depends on radiation timing, radiation dose, and duration of inhibitor exposure. A: Sensitivity to BCL-XL inhibition at 4 (blue), 8 (purple) and 12 (red) days after 15Gy radiation. ). All cohorts were exposed to drug for the same amount of time exposure time (4 days), and were analyzed on the 5th day after plating. Very similar results were obtained with the alternate Bcl-XL inhibitor A1155463, and after induction of senescence with TMZ_-see Supplementary figure 4. B: Impact of prior radiation dose on BCLXL inhibitor sensitivity: A1331852 treatment was initiated 4 days following variable doses of radiation. C: Duration of drug exposure impacts GBM39 vulnerability to A1331852, applied 7days post radiation for 1 hour to 96hours with equal total culture duration prior to analysis. Luminescence values are normalized individually by $0 \mathrm{nM}$ control. Graphs show means \pm SEM of technical triplicates at each concentration. 


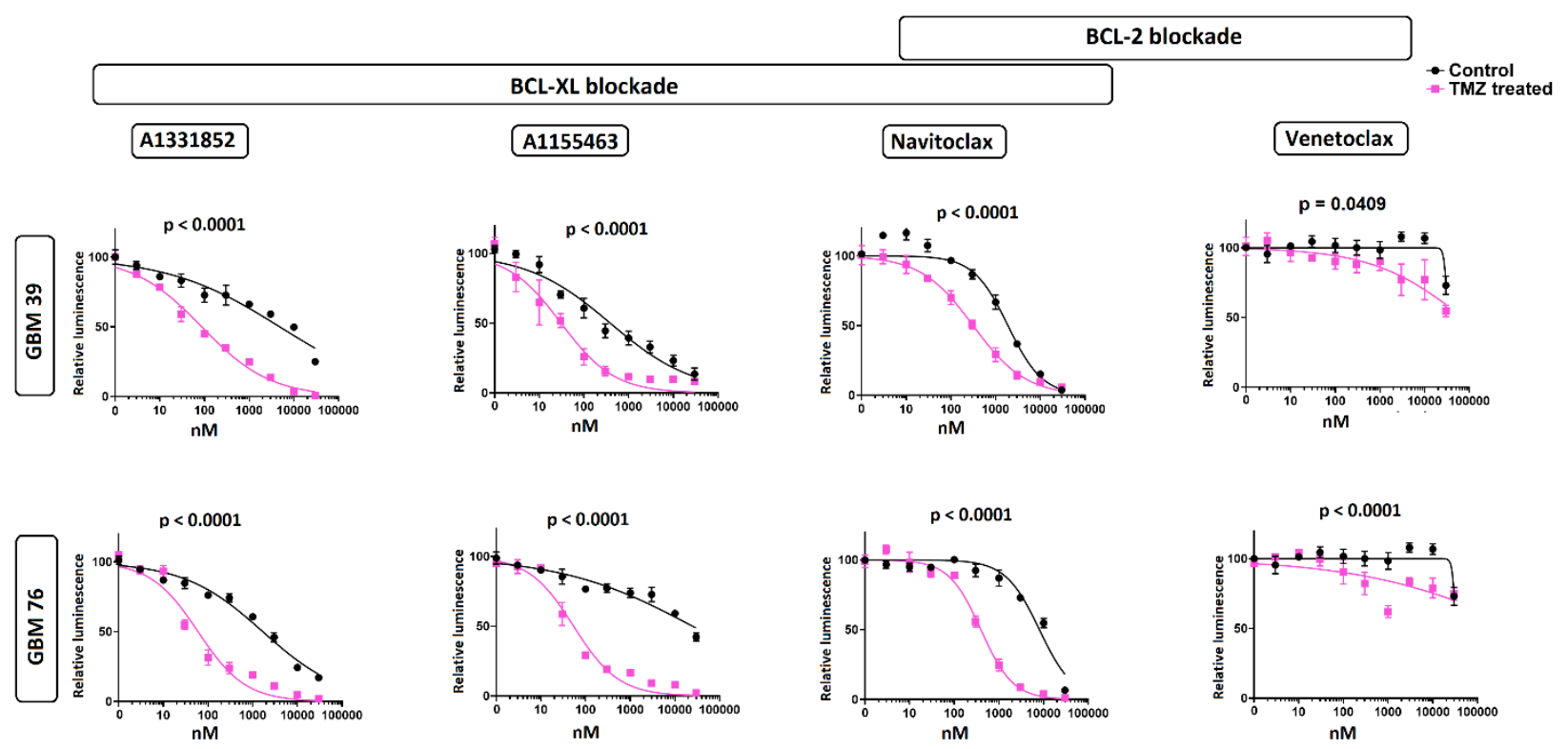

Figure 5: TMZ exposure induces selective vulnerability to Bcl-XL inhibitors. GBM76 and GBM39 were treated with TMZ (100uM) for 7days followed by 14 days TMZ-free media prior to treatment with Bcl-2 family inhibitors as shown. TMZ-treated cells demonstrated selective vulnerability to BCL-XL inhibitors (A1331852, A1155463, Navitoclax), but not to the BCL-2specific inhibitor (Venetoclax). For all experiments, luminescence values are normalized individually to OnM control. All data are means + SEM of 3 technical replicates at each concentration. 

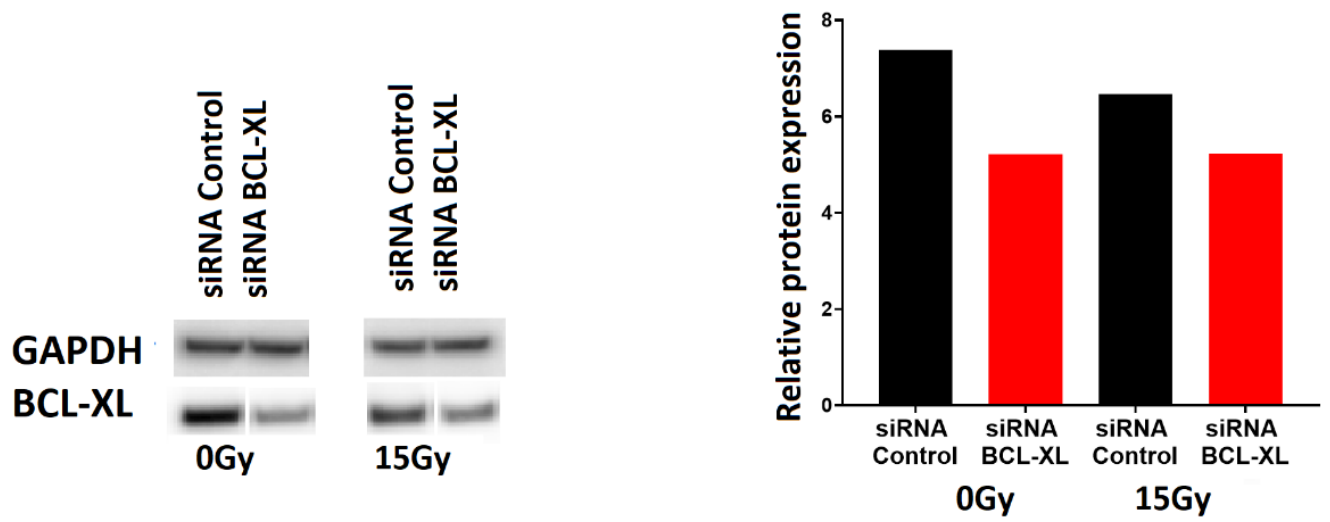

B
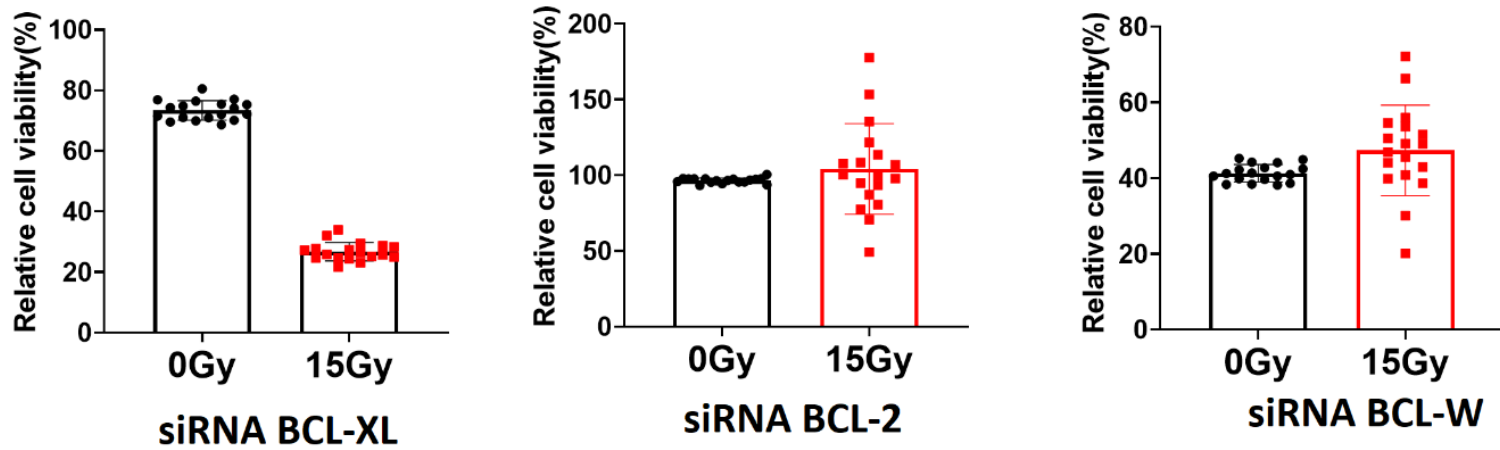

Figure 6: Radiated GBM is selectively vulnerable to Bcl-XL knockdown. A: BCL-XL, BCLW and BCL-2 were knocked down via SiRNA in GBM 39, 7 days after 0Gy, or 15Gy radiation. Data are presented normalized to scrambled control of each group. Representative data one of three different construct of siRNA BCL-XL has shown, Western blot confirmation of knockdown following control siRNA and all constructs of siRNA BCL-XL has shown in Supp. Fig-6. B: Similar knockdown experiments were performed for Bcl-XL, Bcl-2 and Bcl-W. Radiated cells showed decreased survival relative to non-irradiated cells in the Bcl-XL knock down group only $(p<0.0001)$. 

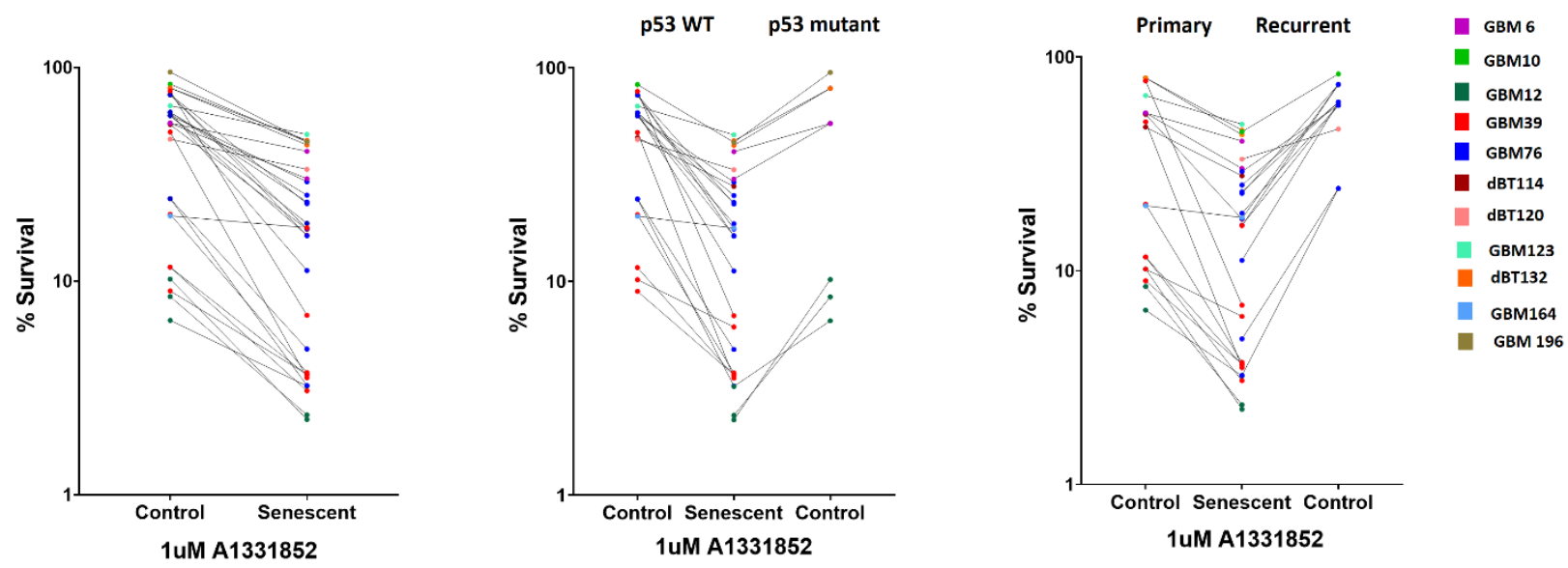

Figure-7: Senescent GBM is selectively vulnerable to BCL-XL inhibitors. A: Relative survival of senescent and proliferating all GBM cell lines tested with 1 uM A1331852 treatment. B: Comparison of selective vulnerability of p53 wild type and mutant senescence Glioma to BCL-XL inhibition. C: Demonstrating senolytic effect of $A 1331852$ across the primary and recurrent Glioma with or without Chemoradiation. 
GBM 76
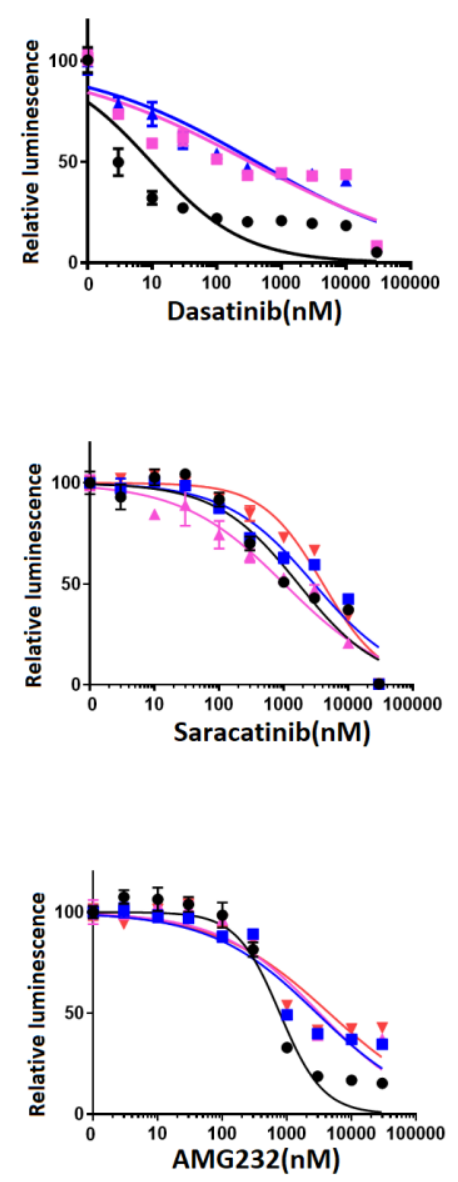
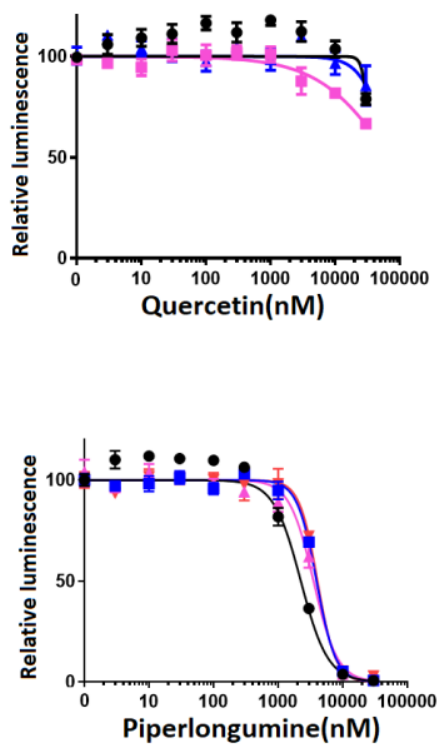

$\mathrm{p}<0.0001$



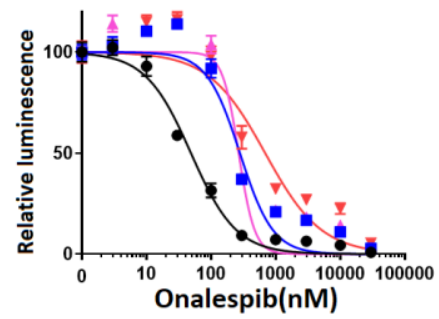

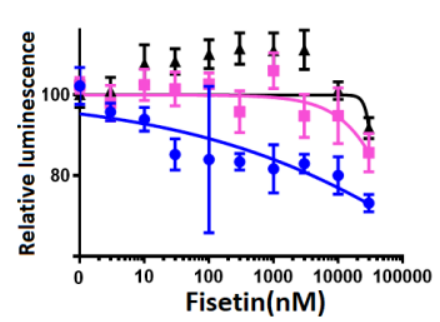
$-10 \mathrm{~Gy}$ radiated $\rightarrow 15 \mathrm{~Gy}$ radiated $\rightarrow 20$ Gy radiated

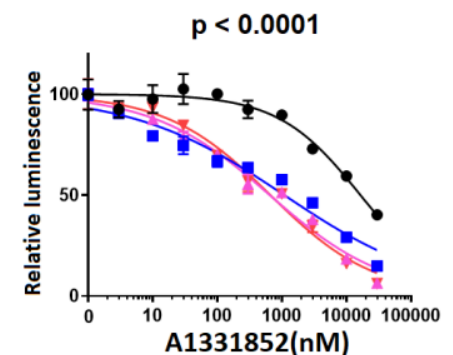

Supplementary Figure 1: Navitoclax and A1331852 ablate radiated GBM 76 (continuation of main figure 2, which shows data for GBM39). Senolytic drug screening in GBM76 cell line with senolytic drugs targeting different anti-apoptotic pathways, Piperlongumine, MDM2 inhibitor (AMG-232), Onalespib, Dasatinib, Quercetin Fisetin, Navitoclax, A1331852 and Saracatinib. Cells were exposed to ten different concentrations of drug for 4days. Black line denotes non radiated control cells, blue line denotes 10Gy, purple line denotes 15Gy and red line denotes $20 \mathrm{~Gy}$ radiated cells. Luminescence values are normalized individually by $0 \mathrm{nM}$ control. All the data are means \pm SEM of triplicates at each concentration. Navitoclax and A1331852 have shown lower IC50 radiated cells comparing to non-radiated control. 
GBM39

$p<0.0001$

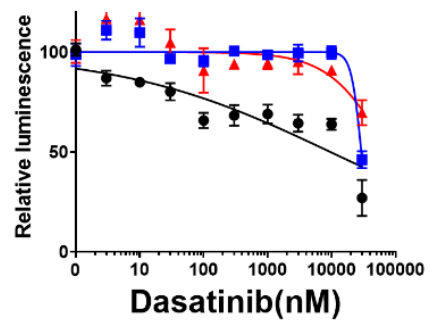

$\mathrm{p}<0.0001$

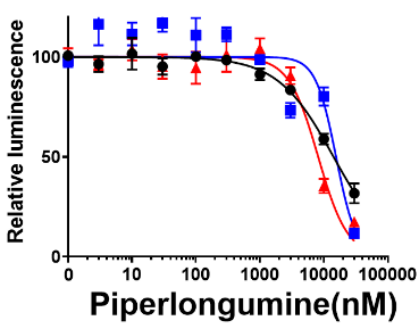

$p=0.0302$

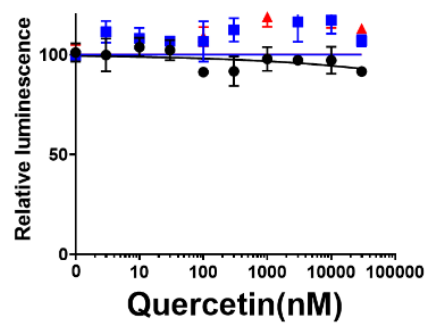

$p<0.0001$

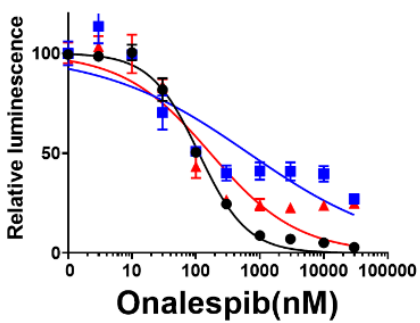

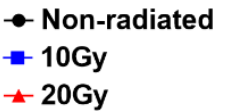

$₫ 20 \mathrm{~Gy}$

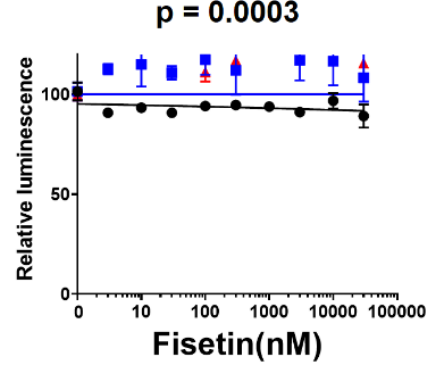

Supplementary Figure-2: Senolytic Candidates evaluated using GBM39 (Continued from Main Figure 2), which shows data for 15Gy. Candidate senolytic drugs were evaluated using GBM39 with and without prior exposure to 10 or 20Gy. Black line denotes non radiated control cells, blue line denotes $10 \mathrm{~Gy}$, and red line denotes $20 \mathrm{~Gy}$ radiated cells. Luminescence values are normalized individually for each radiation dose to the $0 \mathrm{nM}$ control. All the data are means \pm SEM of triplicates at each concentration. Navitoclax and A1331852 have shown lower IC50 radiated cells comparing to non-radiated control. 

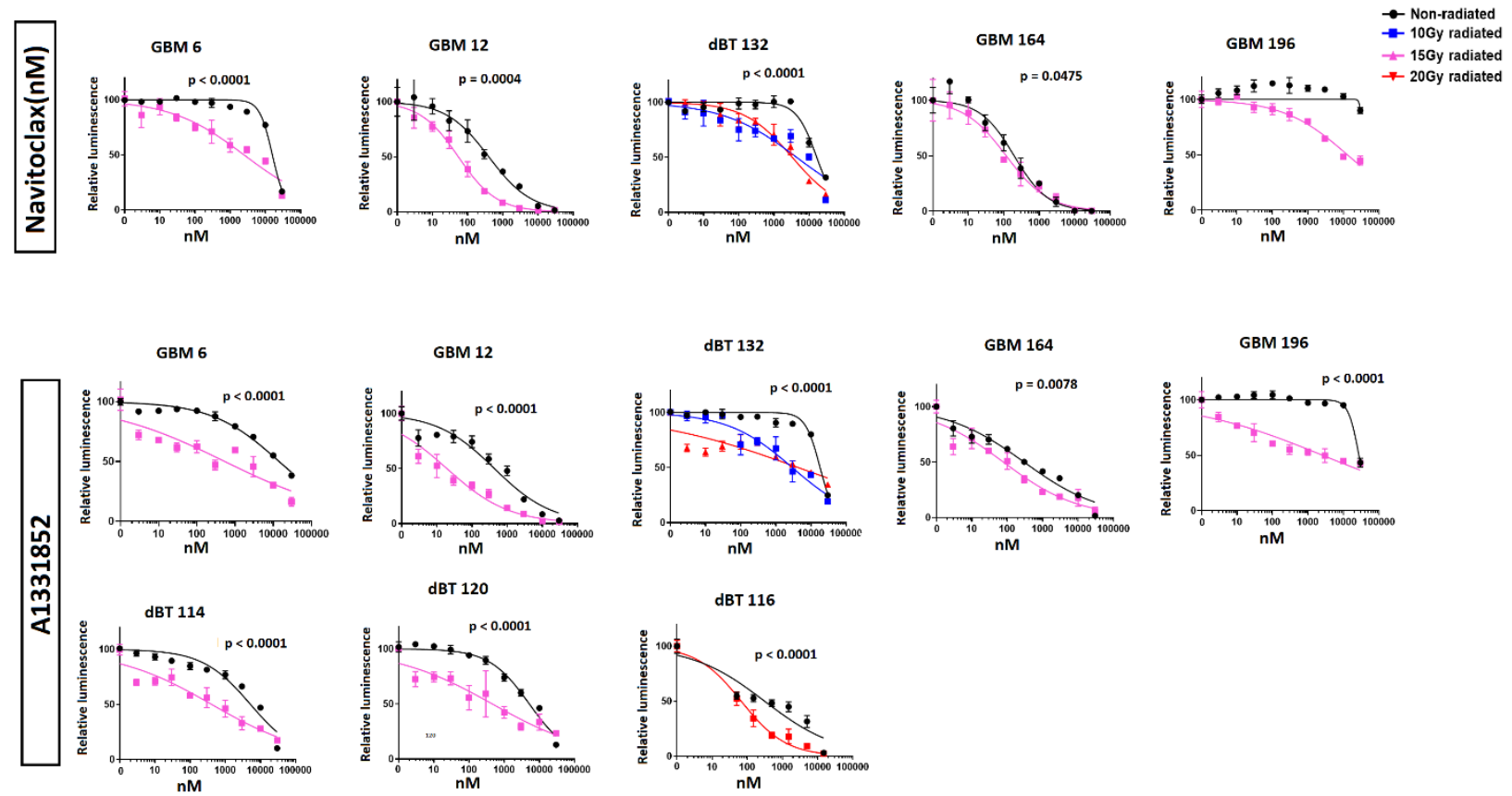

Supplementary figure-3: Multiple radiated GBM cell lines are selectively sensitive to Bcl$\mathrm{XL}$ inhibition. All cell lines tested demonstrated increased sensitivity to BCL-XI inhibition after prior radiation. For all experiments, luminescence values are normalized to the OnM control for that cell line and radiation dose. All data are means + SD of 3 technical replicates at each concentration. 


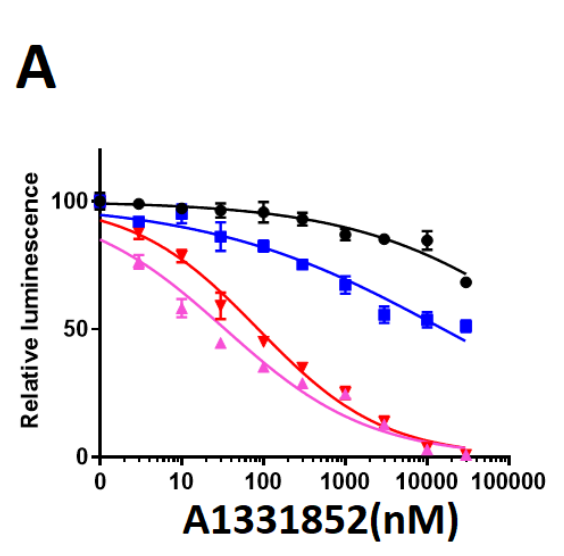

GBM 39

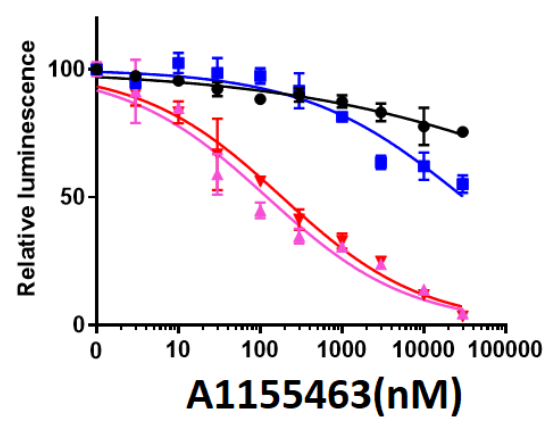

B

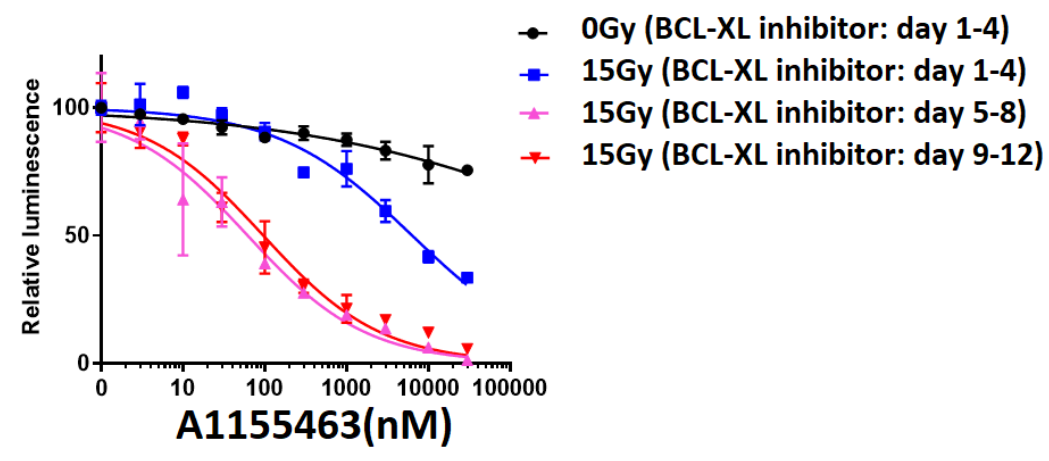

\section{Supplementary figure-4: Navitoclax and A1331852 in TMZ-treated GBM39 (continued from} Main Figure 4a): Evaluation of time-dependency of glioblastoma for BCL-XL inhibitor-mediated ablation. A: Sensitivity to BCL-XL inhibitors (A1331852 and A1155463) at different time-points following TMZ treatment; blue line denotes 4days post TMZ, purple line denotes 8 days post TMZ and red line denotes 12 days post TMZ treatment. B: Sensitivity to BCL-XL inhibitors, A1155463 at different time-points following $15 \mathrm{~Gy}$ radiation. Blue line denotes 4 days post radiation, purple line denotes 8 days post radiation and red line denotes 12 days since radiation with 4 days drug exposure to all cohorts. Luminescence values are normalized individually by $0 \mathrm{nM}$ control. All the data are means ${ }_{ \pm} \mathrm{SEM}$ of triplicates at each concentration. 
A
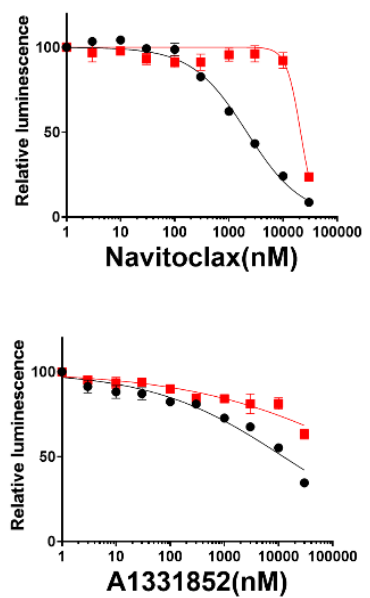

\section{GBM39}
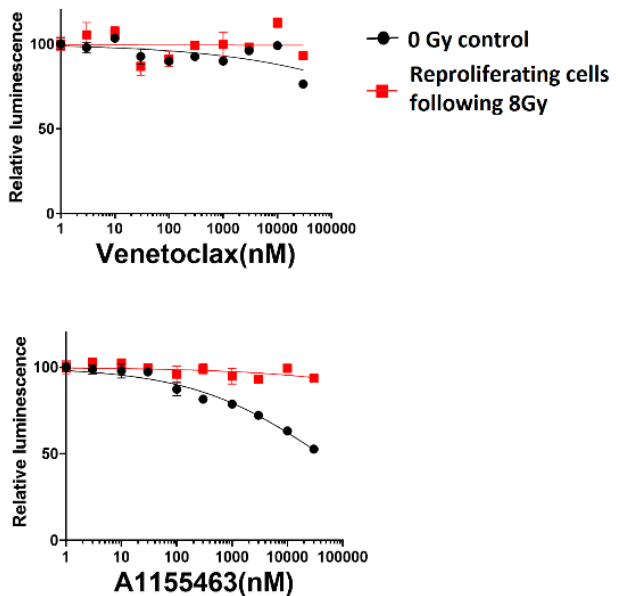

B

GBM39: Reproliferation stage after 8Gy

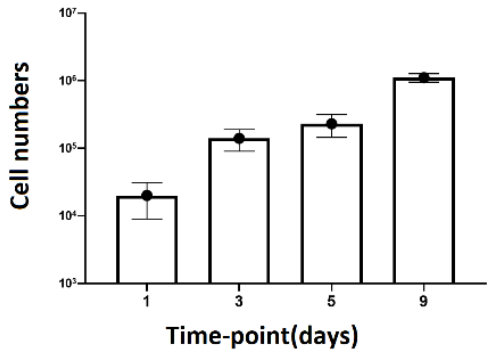

Supplementary figure-5: Previously radiated GBM39 fails to demonstrate sensitivity to Bcl$\mathrm{XL}$ inhibition after re-entering cell cycle. A: BCL-2 family inhibitor drug screening in 8Gy GBM39, those restarted cell proliferation after 6weeks following radiation. Re-proliferation was detected by regular microscopic evaluation, which evident by turning into confluent from $60 \%$ post radiation confluency over 6weeks. B: Increasing number of cells over 9days after regaining proliferation. Cells were re-plated with equal density into 12 wells plate (day 0 ), and cell counts performed at day1,3,5,9. Data represented the mean \pm SD of three technical replicates. Drug screening $(A)$ was performed using the cells harvested at day 5 and 9 . Both demonstrated similar results, here data are shown from day 9.

A

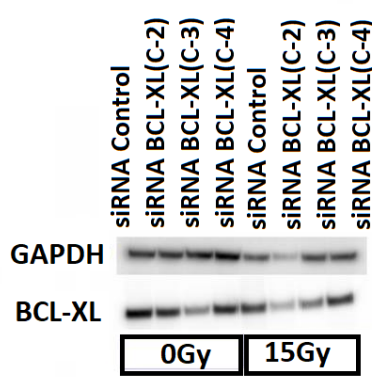

B

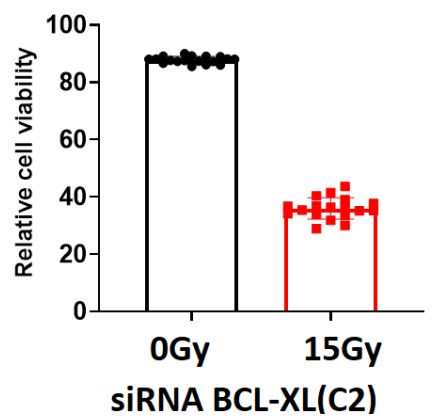

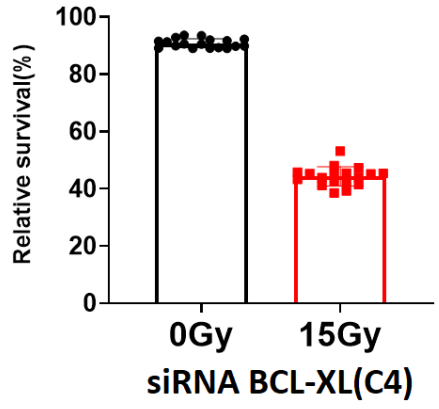

Supplementary figure-6: Radiated GBM is selectively vulnerable to Bcl-XL knockdown. (Continued from main figure 6): BCL-XL protein expression in 0Gy and 15Gy radiated GBM39. A: Western blot confirmation of knockdown following control siRNA and three different constructs of siRNA BCL-XL. B: Relative cell survival following BCL-XL knockdown has shown $15 G y$ radiated cells are more dependent than 0 Gy cells upon $B C L-X L$ for survival. 

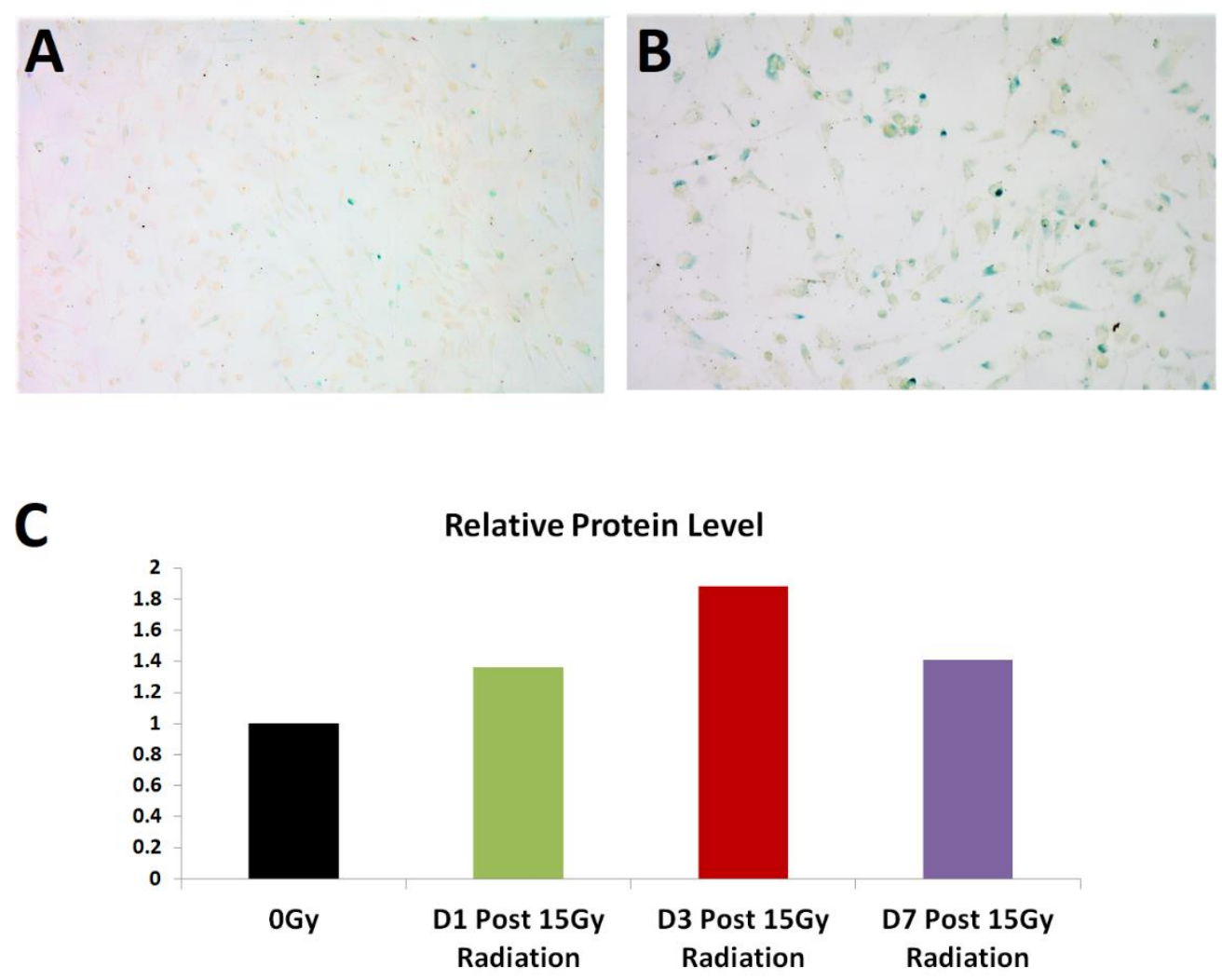

D

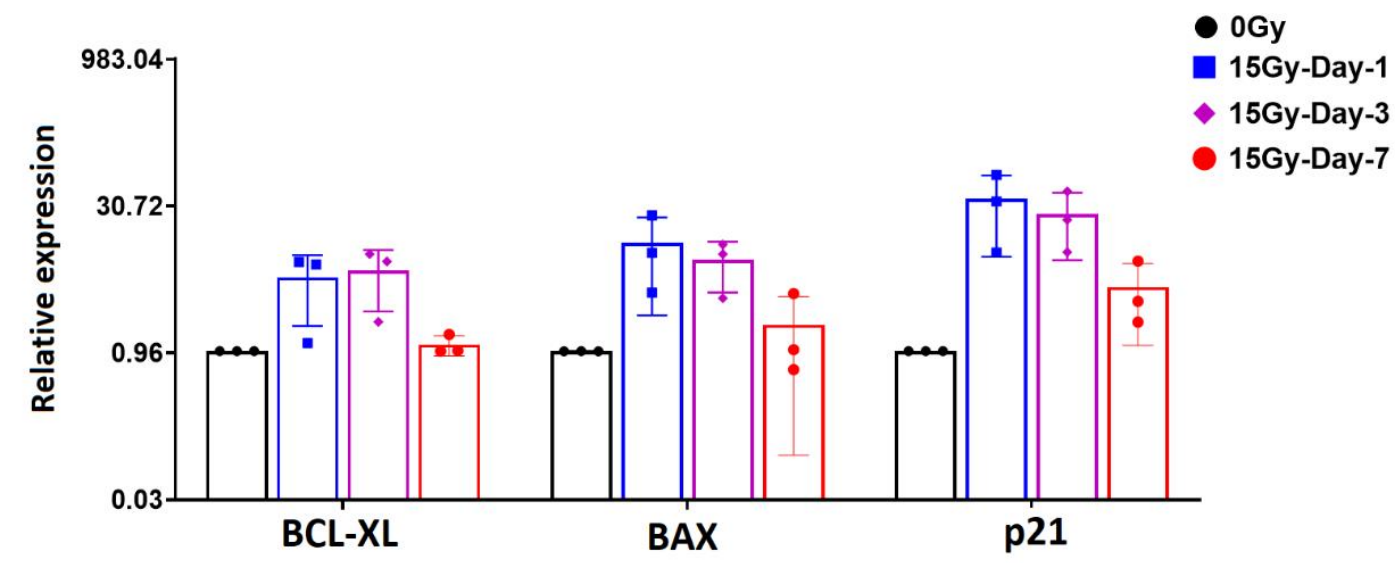

Supplementary figure-7: Confirmation of therapy associated senescence in GBm39. A, B: SAbeta gal staining of control, and TMZ (100uM) treated cells demonstrating presence of senescent glioma in treatment group. C: Western blot analysis showing BCL-XL expression in 0Gy and 15Gy radiated GBM39 over 7days post-radiation. D: qRT-PCR of GBM39 following 15Gy radiation in vitro demonstrates increasing expression of senescence-associated transcripts, p21 and antiapoptotic $\mathrm{BH} 3$ family member $\mathrm{Bcl}-\mathrm{XL}$ over 7 days following radiation. 


\section{References}

1. Stupp R,Mason WP,van den Bent MJ,Weller M,Fisher B,Taphoorn MJ,Belanger K,Brandes AA,Marosi C,Bogdahn U,Curschmann J,Janzer RC,Ludwin SK,Gorlia T,Allgeier A, Lacombe D,Cairncross JG,Eisenhauer E,Mirimanoff RO, Radiotherapy plus concomitant and adjuvant temozolomide for glioblastoma. The New England journal of medicine. 2005 Mar 10; [PubMed PMID: 15758009]

2. Adamski V,Hempelmann A,Flüh C,Lucius R,Synowitz M,Hattermann K,Held-Feindt J, Dormant glioblastoma cells acquire stem cell characteristics and are differentially affected by Temozolomide and AT101 treatment. Oncotarget. 2017 Dec 8; [PubMed PMID: 29296224]

3. Sughrue ME,Sheean T,Bonney PA,Maurer AJ,Teo C, Aggressive repeat surgery for focally recurrent primary glioblastoma: outcomes and theoretical framework. Neurosurgical focus. 2015 Mar; [PubMed PMID: 25727220]

4. Ryken TC,Kalkanis SN,Buatti JM,Olson JJ, The role of cytoreductive surgery in the management of progressive glioblastoma : a systematic review and evidence-based clinical practice guideline. Journal of neuro-oncology. 2014 Jul; [PubMed PMID: 24756348]

5. Knizhnik AV,Roos WP,Nikolova T,Quiros S,Tomaszowski KH,Christmann M,Kaina B, Survival and death strategies in glioma cells: autophagy, senescence and apoptosis triggered by a single type of temozolomide-induced DNA damage. PloS one. 2013; [PubMed PMID: 23383259]

6. Milanovic M,Fan DNY,Belenki D,Däbritz JHM,Zhao Z,Yu Y,Dörr JR,Dimitrova L,Lenze D,Monteiro Barbosa IA,Mendoza-Parra MA,Kanashova T,Metzner M,Pardon K,Reimann M,Trumpp A,Dörken B,Zuber J,Gronemeyer H,Hummel M,Dittmar G, Lee S,Schmitt CA, Senescence-associated reprogramming promotes cancer stemness. Nature. 2018 Jan 4; [PubMed PMID: 29258294]

7. Yeh AC,Ramaswamy S, Mechanisms of Cancer Cell Dormancy--Another Hallmark of Cancer? Cancer research. 2015 Dec 1; [PubMed PMID: 26354021]

8. Carlson BL,Pokorny JL,Schroeder MA,Sarkaria JN, Establishment, maintenance and in vitro and in vivo applications of primary human glioblastoma multiforme (GBM) xenograft models for translational biology studies and drug discovery. Current protocols in pharmacology. 2011 Mar; [PubMed PMID: 21743824]

9. Himes BT,Peterson TE, de Mooij T,Garcia MLMC,Jung MY,Uhm S,Yan D,Tyson J,Li HJL,Parney D,Abukhadra M,Gustafson MP,Dietz AB,Johnson AJ,Dong H,Maus RL,Markovic S, Lucien F,Parney IF, The role of extracellular vesicles and PD-L1 in glioblastoma-mediated immunosuppressive monocyte induction. Neuro-oncology. 2020 Feb 21; [PubMed PMID: 32080744] 10. Jeon HY,Kim JK,Ham SW,Oh SY,Kim J,Park JB, Lee JY,Kim SC,Kim H, Irradiation induces glioblastoma cell senescence and senescence-associated secretory phenotype. Tumour biology : the journal of the International Society for Oncodevelopmental Biology and Medicine. 2016 May; [PubMed PMID: 26586398]

11. Quick QA,Gewirtz DA, An accelerated senescence response to radiation in wild-type p53 glioblastoma multiforme cells. Journal of neurosurgery. $2006 \mathrm{Jul}$; [PubMed PMID: 16871885]

12. Short S,Fielder E,Miwa S,von Zglinicki T, Senolytics and senostatics as adjuvant tumour therapy. EBioMedicine. 2019 Mar; [PubMed PMID: 30737084]

13. Herranz N,Gil J, Mechanisms and functions of cellular senescence. The Journal of clinical investigation. 2018 Apr 2; [PubMed PMID: 29608137] 
14. Kirkland JL,Tchkonia T,Zhu Y,Niedernhofer LJ,Robbins PD, The Clinical Potential of Senolytic Drugs. Journal of the American Geriatrics Society. 2017 Oct; [PubMed PMID: 28869295]

15. Zhu Y,Tchkonia T,Fuhrmann-Stroissnigg H,Dai HM,Ling YY,Stout MB,Pirtskhalava T, Giorgadze N,Johnson KO,Giles CB, Wren JD,Niedernhofer LJ,Robbins PD, Kirkland JL, Identification of a novel senolytic agent, navitoclax, targeting the Bcl-2 family of anti-apoptotic factors. Aging cell. 2016 Jun; [PubMed PMID: 26711051]

16. Zhu Y,Doornebal EJ,Pirtskhalava T,Giorgadze N,Wentworth M,Fuhrmann-Stroissnigg H,Niedernhofer LJ,Robbins PD,Tchkonia T,Kirkland JL, New agents that target senescent cells: the flavone, fisetin, and the BCL-X\{sub\}L\{/sub\} inhibitors, A1331852 and A1155463. Aging. 2017 Mar 8; [PubMed PMID: 28273655]

17. Gentile M,Petrungaro A,Uccello G,Vigna E,Recchia AG,Caruso N,Bossio S,De Stefano L,Palummo A,Storino F,Martino M,Morabito F, Venetoclax for the treatment of chronic lymphocytic leukemia. Expert opinion on investigational drugs. 2017 Nov; [PubMed PMID: 28972395]

18. Woods D,Turchi JJ, Chemotherapy induced DNA damage response: convergence of drugs and pathways. Cancer biology [PubMed PMID: 23380594]

19. Davalli P,Marverti G,Lauriola A,D'Arca D, Targeting Oxidatively Induced DNA Damage Response in Cancer: Opportunities for Novel Cancer Therapies. Oxidative medicine and cellular longevity. 2018; [PubMed PMID: 29770165]

20. Mikuła-Pietrasik J,Niklas A,Uruski P,Tykarski A,Książek K, Mechanisms and significance of therapyinduced and spontaneous senescence of cancer cells. Cellular and molecular life sciences : CMLS. 2020 Jan; [PubMed PMID: 31414165]

21. Rajani KR,Carlstrom LP,Parney IF,Johnson AJ,Warrington AE,Burns TC, Harnessing Radiation Biology to Augment Immunotherapy for Glioblastoma. Frontiers in oncology. 2018; [PubMed PMID: 30854331]

22. Ahmed AU,Auffinger B,Lesniak MS, Understanding glioma stem cells: rationale, clinical relevance and therapeutic strategies. Expert review of neurotherapeutics. 2013 May; [PubMed PMID: 23621311]

23. Almog N, Molecular mechanisms underlying tumor dormancy. Cancer letters. 2010 Aug 28; [PubMed PMID: 20363069]

24. Gulaia V,Kumeiko V,Shved N,Cicinskas E,Rybtsov S,Ruzov A,Kagansky A, Molecular Mechanisms Governing the Stem Cell's Fate in Brain Cancer: Factors of Stemness and Quiescence. Frontiers in cellular neuroscience. 2018; [PubMed PMID: 30510501]

25. Triana-Martínez F,Loza MI,Domínguez E, Beyond Tumor Suppression: Senescence in Cancer Stemness and Tumor Dormancy. Cells. 2020 Feb 3; [PubMed PMID: 32028565]

26. Rossari F,Zucchinetti C,Buda G,Orciuolo E, Tumor dormancy as an alternative step in the development of chemoresistance and metastasis - clinical implications. Cellular oncology (Dordrecht). 2020 Apr; [PubMed PMID: 31392521]

27. Vaubel RA,Tian S,Remonde D,Schroeder MA,Mladek AC,Kitange GJ,Caron A,Kollmeyer TM,Grove R,Peng S,Carlson BL,Ma DJ,Sarkar G,Evers L,Decker PA, Yan H,Dhruv HD,Berens ME, Wang Q, Marin BM,Klee EW,Califano A, LaChance DH,Eckel-Passow JE,Verhaak RG,Sulman EP,Burns TC, Meyer FB,O'Neill BP,Tran NL, Giannini C,Jenkins RB,Parney IF,Sarkaria JN, Genomic and Phenotypic Characterization of a Broad Panel of Patient-Derived Xenografts Reflects the Diversity of Glioblastoma. Clinical cancer research : an official journal of the American Association for Cancer Research. 2020 Mar 1; [PubMed PMID: 31852831] 
28. Williams AB,Schumacher B, p53 in the DNA-Damage-Repair Process. Cold Spring Harbor perspectives in medicine. 2016 May 2; [PubMed PMID: 27048304]

29. Tsuchida N,Gao C,Tsuchida Y,Nakajima T,Nishigaki R, [DNA damage-induced signal pathway of p53 as a tumor suppressor and the gene mutation in human cancer]. Tanpakushitsu kakusan koso. Protein, nucleic acid, enzyme. 2000 Jul; [PubMed PMID: 10897687]

30. Karpel-Massler G,Ishida CT,Bianchetti E,Zhang Y,Shu C,Tsujiuchi T,Banu MA,Garcia F,Roth KA,Bruce JN,Canoll P,Siegelin MD, Induction of synthetic lethality in IDH1-mutated gliomas through inhibition of Bcl-xL. Nature communications. 2017 Oct 20; [PubMed PMID: 29057925]

31. Dalton WB, Yang VW, Role of prolonged mitotic checkpoint activation in the formation and treatment of cancer. Future oncology (London, England). 2009 Nov; [PubMed PMID: 19903065]

32. Jiao Y,Feng Y,Wang X, Regulation of Tumor Suppressor Gene CDKN2A and Encoded p16-INK4a Protein by Covalent Modifications. Biochemistry. Biokhimiia. 2018 Nov; [PubMed PMID: 30482142]

33. Witkiewicz AK,Knudsen KE,Dicker AP,Knudsen ES, The meaning of p16(ink4a) expression in tumors: functional significance, clinical associations and future developments. Cell cycle (Georgetown, Tex.). 2011 Aug 1; [PubMed PMID: 21775818]

34. McKenzie HA,Fung C,Becker TM,Irvine M,Mann GJ,Kefford RF,Rizos H, Predicting functional significance of cancer-associated p16(INK4a) mutations in CDKN2A. Human mutation. 2010 Jun; [PubMed PMID: 20340136]

35. Bussian TJ,Aziz A,Meyer CF,Swenson BL,van Deursen JM,Baker DJ, Clearance of senescent glial cells prevents tau-dependent pathology and cognitive decline. Nature. 2018 Oct; [PubMed PMID: 30232451]

36. Schindler MK,Forbes ME,Robbins ME,Riddle DR, Aging-dependent changes in the radiation response of the adult rat brain. International journal of radiation oncology, biology, physics. 2008 Mar 1; [PubMed PMID: 18164853]

37. Gonzalez-Meljem JM,Apps JR,Fraser HC,Martinez-Barbera JP, Paracrine roles of cellular senescence in promoting tumourigenesis. British journal of cancer. 2018 May; [PubMed PMID: 29670296]

38. Kirkland JL,Tchkonia T, Cellular Senescence: A Translational Perspective. EBioMedicine. 2017 Jul; [PubMed PMID: 28416161]

39. Leverson JD,Phillips DC,Mitten MJ,Boghaert ER,Diaz D,Tahir SK,Belmont LD,Nimmer P,Xiao Y,Ma XM, Lowes KN,Kovar P,Chen J,Jin S,Smith M,Xue J,Zhang H,Oleksijew A,Magoc TJ,Vaidya KS,Albert DH,Tarrant JM, La N,Wang L,Tao ZF, Wendt MD, Sampath D, Rosenberg SH,Tse C, Huang DC,Fairbrother WJ,Elmore SW,Souers AJ, Exploiting selective BCL-2 family inhibitors to dissect cell survival dependencies and define improved strategies for cancer therapy. Science translational medicine. 2015 Mar 18; [PubMed PMID: 25787766]

40. Souers AJ,Leverson JD,Boghaert ER,Ackler SL,Catron ND,Chen J, Dayton BD, Ding H,Enschede SH,Fairbrother WJ,Huang DC,Hymowitz SG,Jin S,Khaw SL,Kovar PJ,Lam LT, Lee J,Maecker HL,Marsh KC,Mason KD,Mitten MJ,Nimmer PM,Oleksijew A,Park CH,Park CM,Phillips DC,Roberts AW,Sampath D,Seymour JF,Smith ML,Sullivan GM, Tahir SK, Tse C, Wendt MD, Xiao Y, Xue JC, Zhang H, Humerickhouse RA,Rosenberg SH,Elmore SW, ABT-199, a potent and selective BCL-2 inhibitor, achieves antitumor activity while sparing platelets. Nature medicine. 2013 Feb; [PubMed PMID: 23291630] 